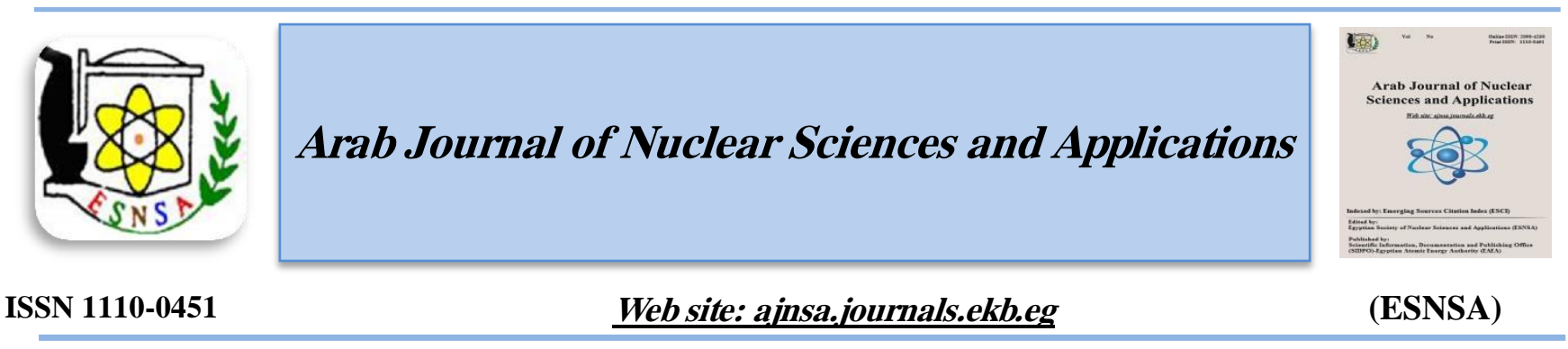

\title{
Improvement of Low-Grade Rutile Using Chemical and Physical Processes
}

\author{
A.A. El-Shennawy \\ Nuclear Materials Authority, Cairo, Egypt
}

Received $25^{\text {th }}$ Dec. 2017 Accepted $11^{\text {th }}$ Mar. 2018

\begin{abstract}
Rutile is a very important mineral for several industrial applications. In the present work, the physical and chemical methods used to upgrade low grade rutile will be discussed. A sample of $10 \mathrm{Kg}$ was collected from Abu Khashaba beach area at the Mediterranean cost, Egypt. The leaching process for rutile mineral whereby iron coatings around rutile particles are removed using sulphuric acid of $(20 \mathrm{wt} \%$ concentration) at $160^{\circ} \mathrm{C}$. The after leaching sample is sent for physical separation processes which include up-current classifiers, gravimetric separation, hydraulic separation and magnetic separation. Stereo microscope and XRF analyses were used to study the heavy and light mineral fractions. Identification of the treated rutile sample is established and the results reveal that, at optimum conditions, a high grade rutile can be produced containing $95.8 \%$ Ti with $0.8 \% \mathrm{Fe}, 1.8 \% \mathrm{Zr}$ and $0.80 \%$ Nb.
\end{abstract}

\section{Keywords: Rutile,Upgrading, Chemical treatment, Physical beneficiation}

\section{Introduction}

The Egyptian black sandsare the end products of the disintegrated materials from the igneous and metamorphic rocks, and its deposits extend along the Mediterranean coast from Abu Qir in the west to Rafah in the east $[2,3]$. These deposits occur as beach sediments and coastal sand dunes Fig (1). The east Rosetta area contains relatively enriched beach black sands. The rutile content of the Rosetta are ranges from $0.05 \mathrm{wt} \%$ in the uppermost meter to $1.5 \mathrm{wt} \%$ in the highly concentrated surficial beach black sands (maximum depth of $20 \mathrm{~cm}$ ) in the eroded areas. Rutile is among the minerals having the highest refractive indices at visible wavelengths of any known crystal. It also exhibits particularly large birefringence and high dispersion. Owing to these properties, it is useful for the manufacture of certain optical elements, especially polarization optics, for longer visible and infrared, wavelengths up to about $4.5 \mu \mathrm{m}$. Rutile is valued for its opacity strength (commonly called hiding power) and brightness. Other important features of titanium dioxide pigments have excellent resistance to chemical attack, good thermal Stability and more resistant to UV light than anatase, and is preferred for paint, inks, plastics, especially those exposed to outdoor conditions. The major consumer industries for titanium dioxide pigments are mature sectors in high-resources countries where they are used for surface coatings, paper, paperboard and plastics. Therefore, consumption of titanium dioxide tends to parallel general economic trends. Paint and coating applications have the largest global use, while plastics and paper account for most of the remainder. The total world consumption of titanium dioxide in 2001 was: coatings $55 \%$, plastics and rubber $24 \%$, paper $12 \%$, printing inks $3 \%$ and others:6\%.In 2005, the world consumption was as follows: coatings $58 \%$, resistance to UV degradation rutile pigment is

Corresponding author: a.elshennewy@ hotmail.com

DOI: 10.21608/ajnsa.2018.2406.1029.

(C) Scientific Information, Documentation and Publishing Office (SIDPO)-EAEA 
plastics and rubber $23 \%$, paper $11 \%$ and others $8 \%$ Figure (2).Some other uses of titanium dioxide include catalysts, ceramics, coated fabrics and textiles, floor coverings and roofing granules[4].The annual world production of titanium dioxide is5.1 million tons where, the production of Europe, US and China are 1.4,1.4 and 1.7 million tons respectively. Much smaller amounts of titanium dioxide are used as semi- conductors and to catalyze the photodecomposition of water into hydrogen and oxygen. It also has a high dielectric constant and a high resistance; hence, it is used in capacitors manufacture. The strong bonding between titanium and oxygen gives great thermal stability, so its melting is $2100 \mathrm{~K}$, it is thus used as a ceramic material and also used to increase the acid resistance of vitreous enamels.

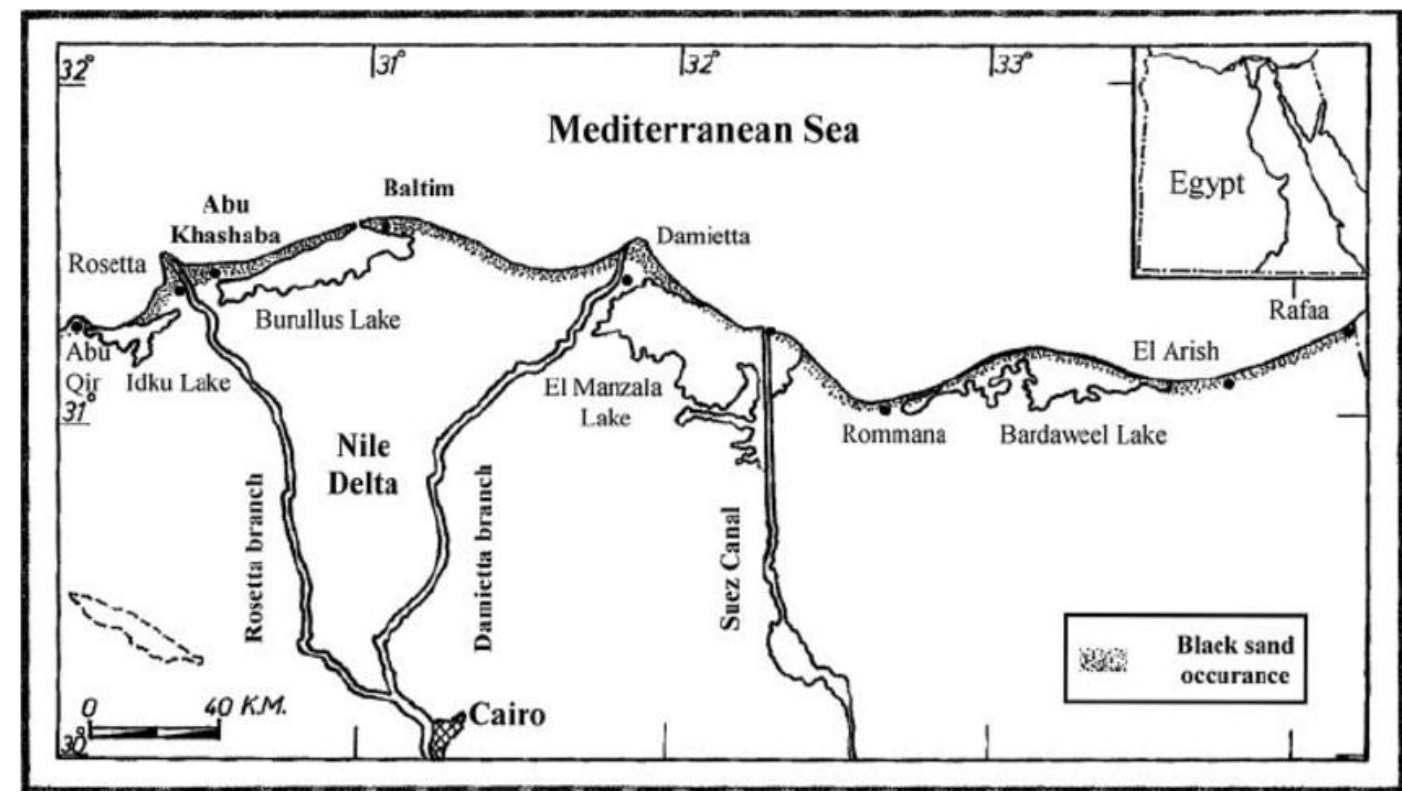

Figure (1): Distribution of the black sand deposits in Egypt

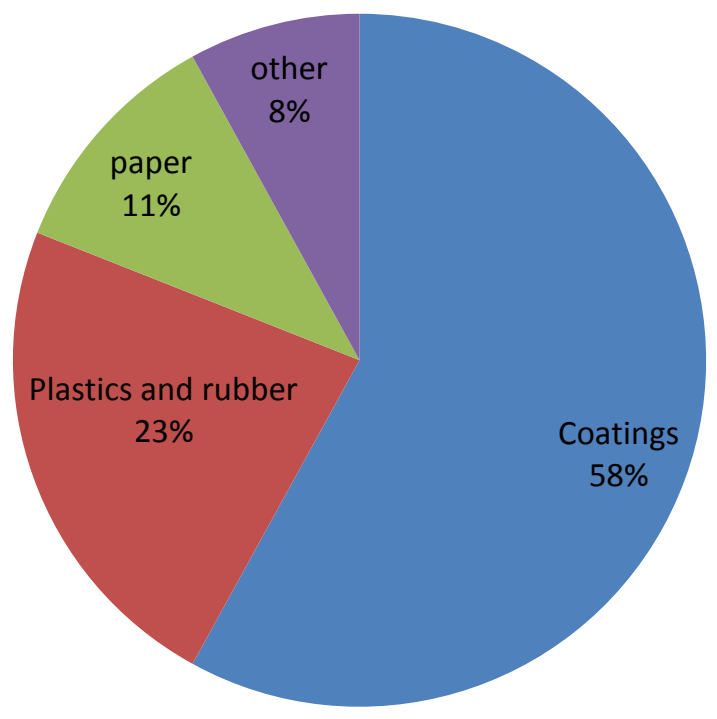

Figure (2): Uses of titanium dioxide 
Iron coatings around rutile particles are the most detrimental impurities and can be reduced through the leaching process via the addition of sulphuric acid to rutile mineral at $160^{\circ} \mathrm{C}$ whereby iron is removed. After, the leaching process, treated rutile was subjected to further physical processing which is to be adopted for the effective removal of the detrimental impurities that may be in intimate association with the mineral quite often superficially

Physical process is used to achieve the aims of this investigation are separation by up-current classifiers (act on the differences in size and density of mineral particles), gravimetric separation(depends on the difference of specific gravity between the important minerals and the gangue.), hydraulic separation(may be defined as the separation of solid particles into two or more products according to their velocities when falling through a fluid medium generally water is used as fluid medium.) and magnetic separation(this machine is used for the continuous separation of small magnetic particles from certain minerals to produce mineral purification).The results of this study led to achieve the desired product of high grade rutile which is imperative to meeting market requirements, that customers demand for using in coatings, plastics, rubber, paper and printing inks.

\section{Materials and Method \\ Materials}

In this work, a sample of $10 \mathrm{Kg}$ low grade rutile separated from black sands of Abu Khashaba beach area at the Mediterranean coast is used. After characterization of the raw material by X-ray fluorescence and stereo microscope, it was subjected to leaching and physical processes.

\section{Methods}

The techniques used for beneficiation the low grade of rutile sample involves:

- Leaching process for the rutile sample through chemical treatment using sulphuric acid to eliminate most of impurities from the rutile surface mainly iron

- Physical processes of ore dressing for further beneficiation using separation techniques of upcurrent classifiers, gravimetric separation hydraulic separation and magnetic separation that depend on the physical properties of the constituents

The following methods were applied in the present work:

\section{1-UP-Current classifiers}

Just enough water was injected through perforated spray pipes, providing a rising up - current of water. Mineral feed entering the top of the classifier meets the rising current and a mechanical stirrer of I HP and stirring speed $200 \mathrm{rpm}$. The interaction of the rising current and the settling solids creates a fluidized bed of particles that causes fine and low density mineral grains to rise over the over flow weir together with the process water [1]. Coarse and higher density grains pass through the fluidized bed to the lower topered dewatering section Figure (3).Up current classifiers are used for mechanically eliminating impurities stuck on the surfaces of the rutile particles, in addition to clean and remove all the slimes and fine quartz from the rutile particles to get a rutile sample containing all mineral grains free from slimes. Then, the cleaned sample was transferred to the leaching process and the tailing (slimes and low density mineral grains) was filtered, dried, weight and bagged for analysis.

\section{2-Leaching process}

Acid leaching for the rutile sample was carried out using a glass reactor provided with a mechanical agitator of teflon - coated stirring rod. Sulphuric acid of $20 \mathrm{wt} \%$ concentration was poured in the reactor then heated to $160 \mathrm{oC}$ and after a certain time (30 minutes) $[5,6,8,11,13]$ the suspension of the reaction products was immediately filtered, dried, weighted and bagged for analysis and the treatment rutile sample was transferred to the hydraulic separation

\section{3-Hydraulic separation}

After various trials, it was possible to design a hydraulic classifier to get a higher quality of mineral grains. The hydraulic classifier is a device characterized by the use of water additional to that contained in the feed pulp, and introduced so that its direction of flow opposes that of the settling particles.

Corresponding author: a.elshennewy@hotmail.com

DOI: 10.21608/ajnsa.2018.2406.1029.

(C) Scientific Information, Documentation and Publishing Office (SIDPO)-EAEA 


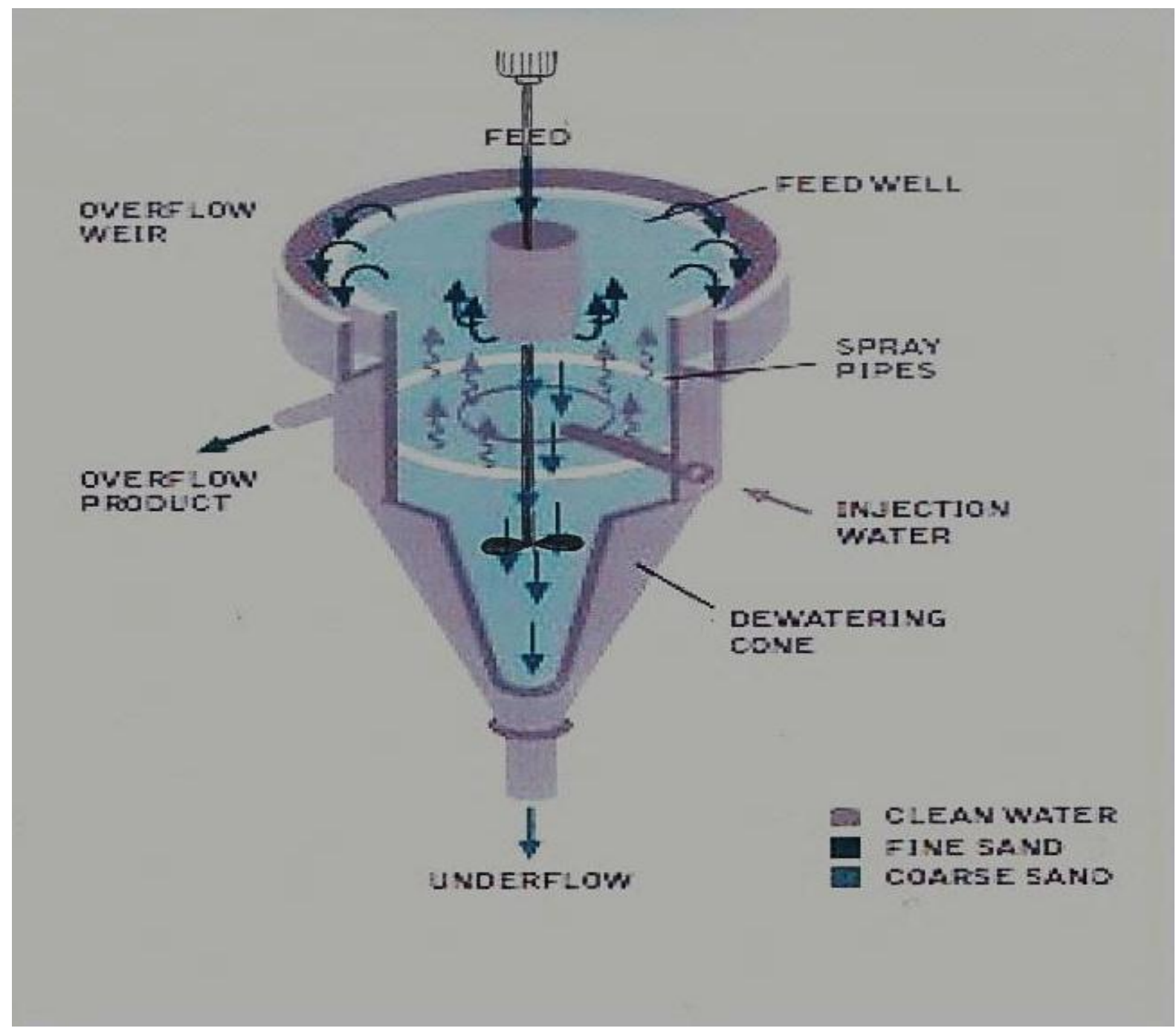

Figure (3): Longitudinal section ofup-current classifiers

\section{Description of the device}

This device consists of several conical glass units connected to each other by a glass connection which connects the top of the first glass unit with the bottom of the second glass unit, and the top of the second glass unit with the bottom of the third glass unit, etc. These units are mounted on a chassis of ascending heights in a way that the ascending distance between these units is the equal to finally take a ladder form as shown in Figure (4.a) and Figure (4.b). Each one of these glass units is connected to an independent water source. The intensity of each water source can be controlled by a special lock that pushes the water stream through this unit from the bottom up. There is also, beside each lock of the waterpushing locks, another lock that pulls the materials being separated and concentrated in each one of these glass units. Also, at the end of each conical glass, there is a small side lock through which the deposits layers above each other can be separated by controlling the opening of the side lock through which the first deposited layer can be withdrawn then the second deposited layer. This lock is additionally used to wash these glass units by opening the lock responsible for pushing the water stream from bottom up then emptying this stream through the side lock that is attached to each conical glass.

\section{How this device works}

The sample to be separated and the contained materials in it that have high economic value to be 
concentrated is put in the first glass unit which is mounted in the lower level. This is done after filling a part of this unit with water so that the level of both, the water and the sample, in this unit is lower than the level of the glass connection that connects the first unit to the second unit. Then, the lock that controls pushing the water stream from bottom top is adjusted through this unit so that the stream stirs the sample lightly. This stream will carry the materials with the lower specific density from the first glass unit and transfer it to the second glass unit so that the running water stream from bottom top inside the glass unit stirs the transferred materials from the first unit and that is after adjusting the rate of water stream burst. This stream will carry the lower density materials and transfer it to the third glass unit to repeat what happened in the first and second units, etc. This process is repeated until reaching the last glass unit so that the water stream getting out of this unit is received in a container to precipitate what it contains if the water stream is still loaded with some slimes. There are several factors that must be taken into account when operating this device in order to accomplish the desired purpose of it, and they are:

-Adjusting the rate of water stream burst from bottom to top inside each one of the units of the hydraulic separation device. This depends on the study of the natural characteristics of the materials desired to be separated and concentrated.

-Adjusting the amount water put in the first glass unit of the device so that the level of both the water and the sample in this unit is lower than the level of the glass connection that connects the first unit with the second unit. This allows the running water stream from bottom to top to stir the sample thoroughly and also allowing the particles of the material to be separated to be arranged inside this unit before it is transferred to the second stage.

-Increasing the number of the constituent glass units of the device because this helps in the process of separating various materials that are desired to be separated and reaching high levels of concentration

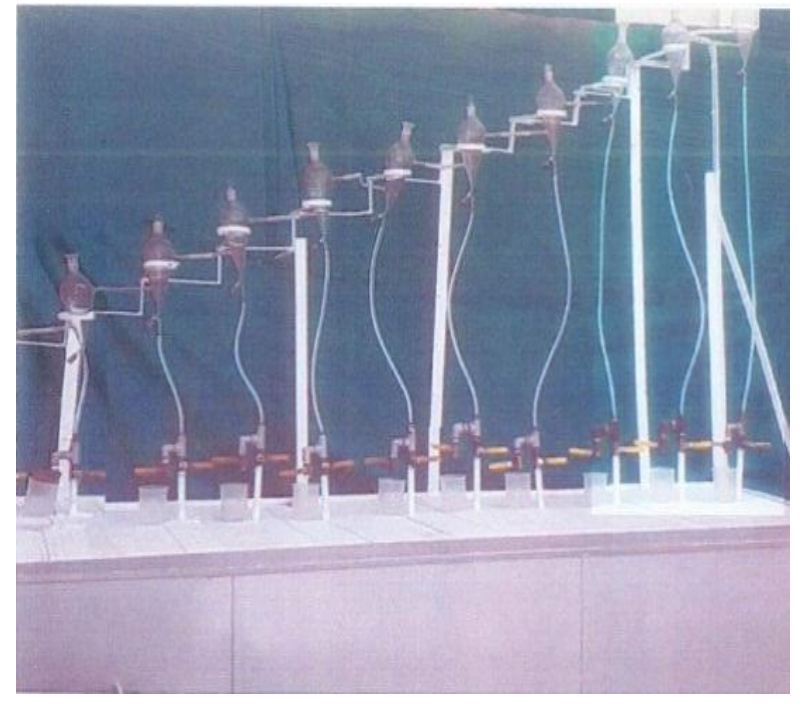

Figure (4.a): Hydraulic separation device

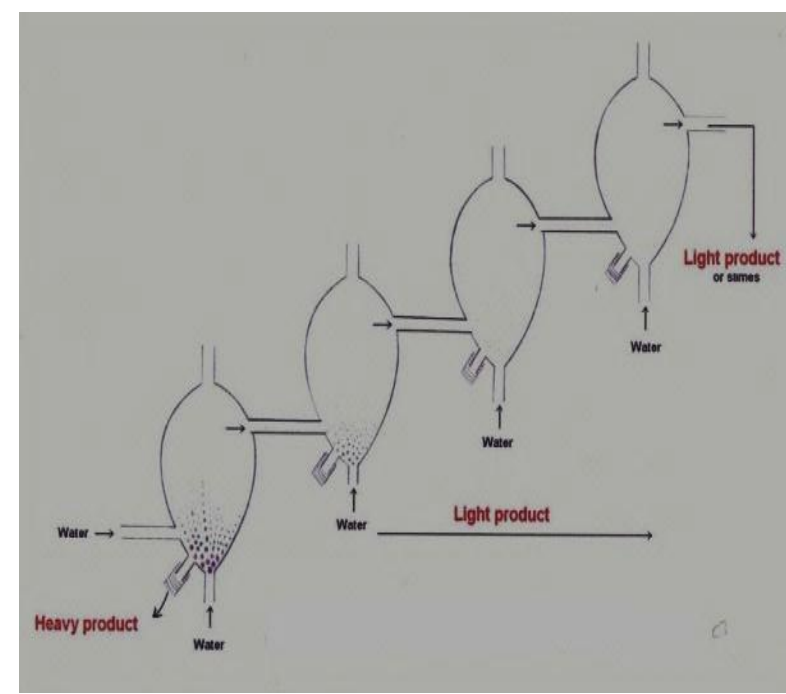

Figure (4.b): Principle of hydraulic classifier 4-Gravimetric separation

This was achieved by the shaking table concentrator which consists of a sloping deck with ariffled surface. A motor drives a small arm that shakes the table along its length, parallel to the rifle and rifle pattern. The riffles are arranged in such a manner that heavy material is tapped and conveyed parallel to the direction of the oscillation Figure (5).Water is added on the top of table perpendicular to the table motion. The heaviest and coarsest particles move to one end of the table while the lightest and to the finest particles tend to wash over the riffles and to bottom edge $[7,9,12,14-16]$. Intermediate points between these extremes provides recovery of the middling ( 


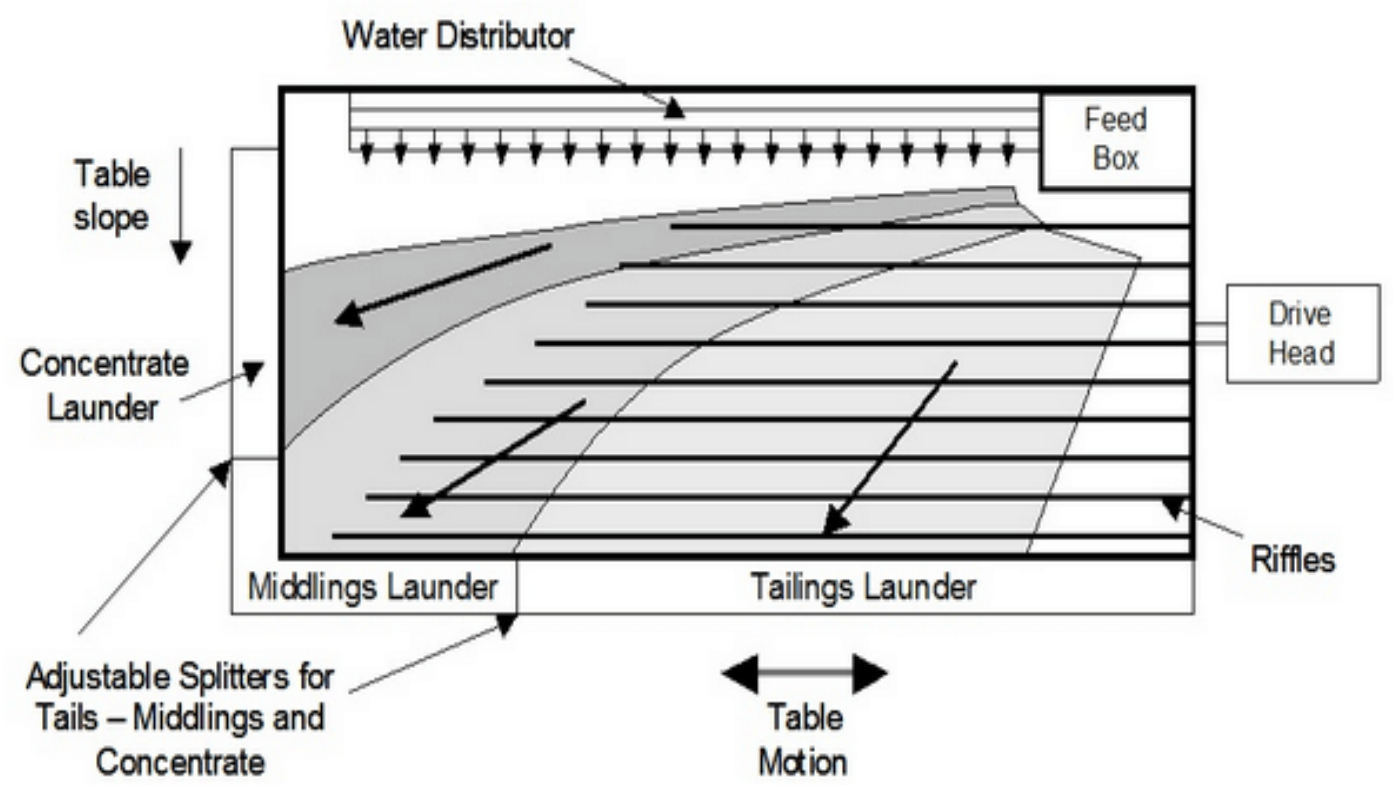

Figure (5): Distribution of shaking table

intermediate size and density ) particles. The leached sample was prepared washing water. Both the stroke speed(70rpm), table slope (2 degree) and water flow rate $(1.3 \mathrm{~L} / \mathrm{min})$ are adjustable.

\section{Magnetic separation}

The concentrated rutile sample, coming from the previous step, was dried and conducted by dry magnetic separation using the Induced Roll Separator at magnetic intensity of 1.5 Tesla (15000 Gauss). The rutile (grade B) being treated is fed from a hopper or vibratory feeder at a controlled rate on to a high intensity magnetic. The magnetic material attaches itself onto the role face or is deflected towards the roll. The non-magnetic material is thrown off the face at a normal trajectory. The magnetic material is discharged off the roll face at a point of lower magnetic intensity aided by a brush. A splitter plat is interposed between the two product streams $[10,15,16]$.As a result, magnetic materials are separated from the concentrate rutile that affects the quality of the upgraded final rutile concentrate. Both the magnetics(impurities) and non - magnetic (product rutile)materials were weighted and bagged for analysis.

Based on the laboratory processing studies conducted on the raw rutile sample for beneficiation of low-grade rutile sample, a beneficiation flow sheet is suggested as follows Figure (6). 


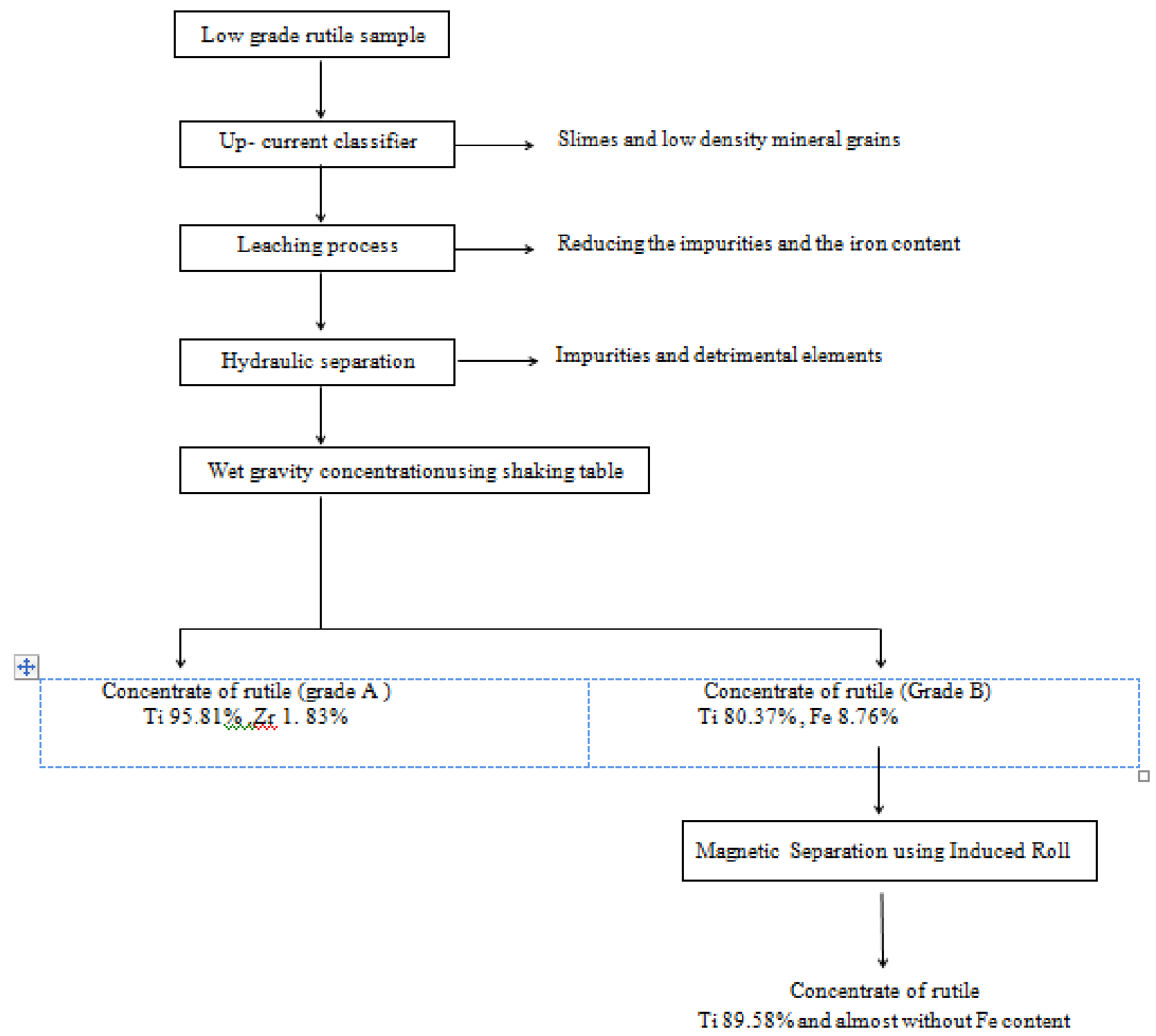

Figure (6): A simplified flow sheet showing the various concentration and separation steps for

\section{Results and Discussion}

Before investigating the physical and chemical processes for beneficiation of low-grade rutile sample, it is reasonable to throw the light on the composition of rutile sample. The results of chemical analysis of the sample under investigation by means of $\mathrm{X}$-ray fluorescence is illustrated in Figure (7).It shows that rutile sample contains $\operatorname{Ti}(62.96 \%), \operatorname{Zr}(10.43 \%), \quad \operatorname{Fe}(12.32 \%)$, $\mathrm{Si}(4.36 \%), \mathrm{Zn}(1.167 \%), \mathrm{Ca}(1.69 \%), \mathrm{Cr}(1.69 \%)$, $\mathrm{Pb}(1.65 \%), \quad \mathrm{V}(1.06 \%), \operatorname{Mn}(0.98 \%)$ and $\mathrm{Nb}(0.60 \%)$. Characterization showed that sample cannot directly be used for any value added industrial applications. 
The rutile sample was first subjected to mechanical elimination of the impurities stuck on the rutile particles surfaces by mean of up current classifier. The collected tailing (slimes and low density mineral grains) were filtered and dried for analysis by XRF. The results are shown in Figure (8) which it appears that the eliminated impurities from the raw rutile sample such as $\mathrm{Si}(33.06 \%), \mathrm{Ca}(17.71$

$\%), \mathrm{Fe}(17.84 \%), \mathrm{Al}(11.19 \%), \operatorname{Zr}(3.71 \%), \mathrm{K}(1.79$ $\%), \quad \operatorname{Mn}(1.40 \%), \mathrm{Zn}(1.34 \%), \quad \mathrm{Nb}(0.10 \%)$ and $\mathrm{Pb}(0.50 \%)$.

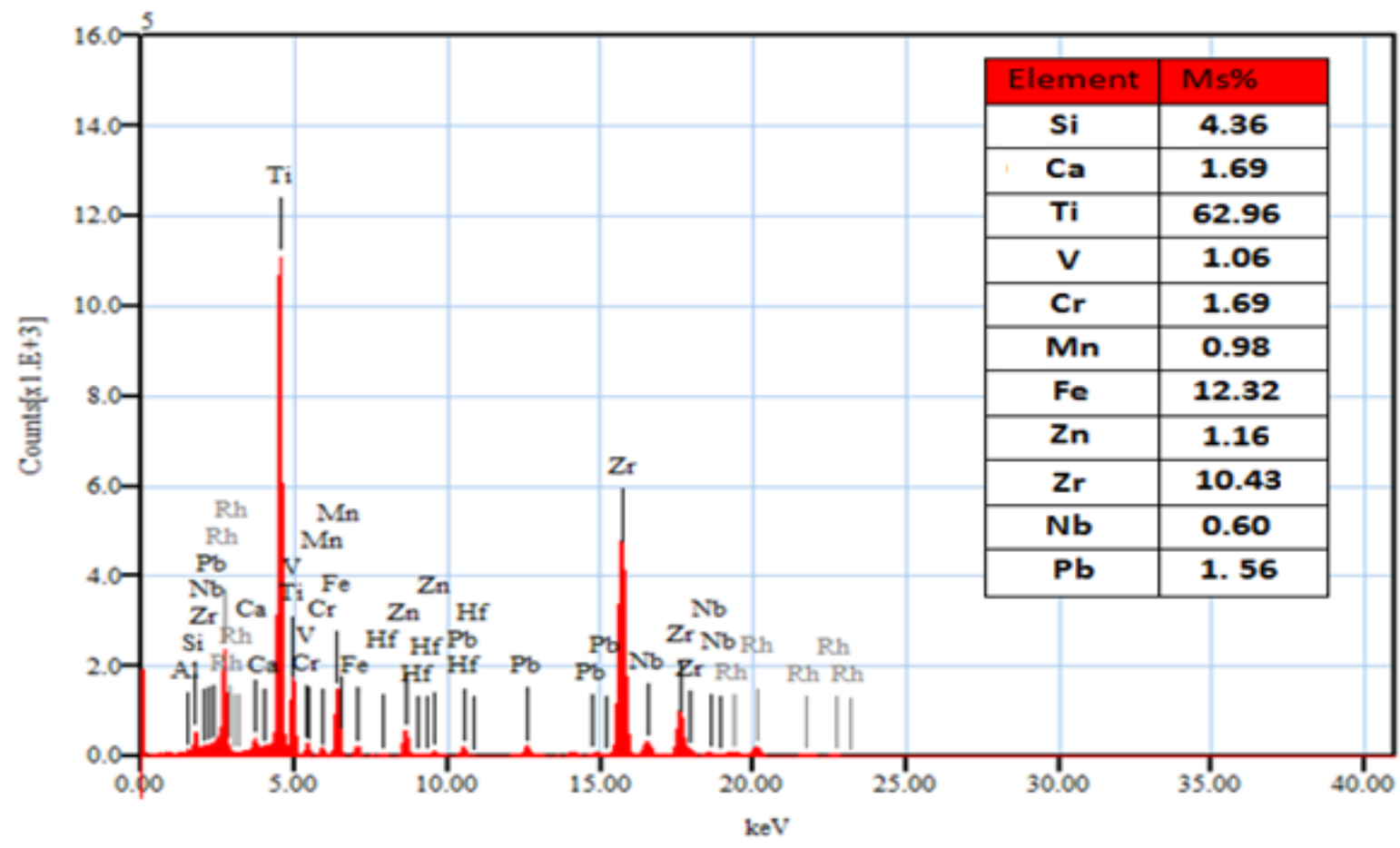

Figure (7): XRF pattern of the original rutile sample

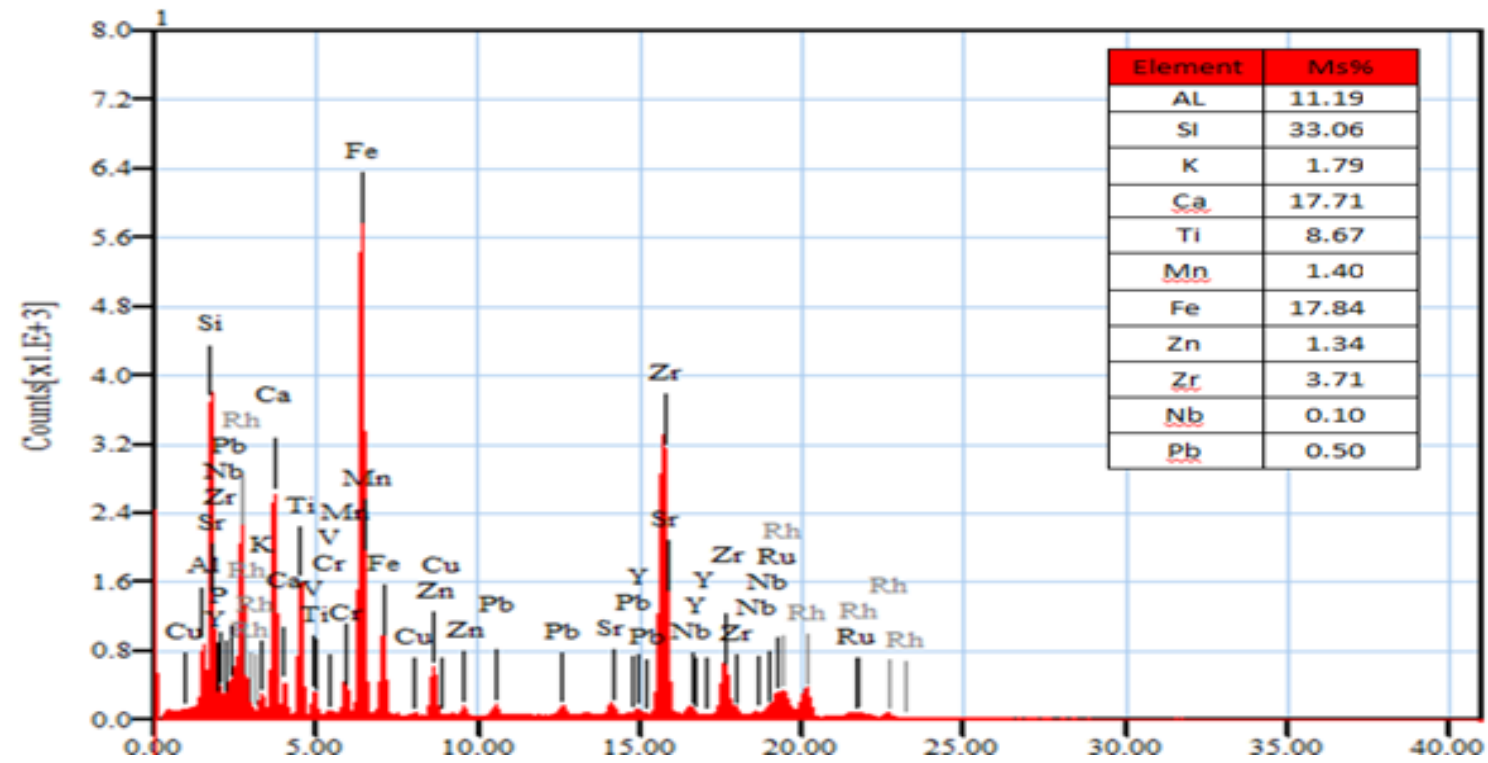

Figure (8): XRF pattern of the collected tailing from the up-current classifier 
Leaching of iron and calcium oxides coating rutile particles with sulphuric acid $20 \mathrm{wt} \%$ at $160^{\circ} \mathrm{C}$ has been done for reducing them from the rutile sample and formation iron sulphateFe ${ }_{2}\left(\mathrm{SO}_{4}\right)_{3}$. The collected impurities were filtered and dried for analysis by XRF. The results of XRF Fig.(9) indicates that the leaching process iron content $22.20 \%$ and calcium $2.15 \%$ and improves the lowgrade rutile sample.

The rutile sample, after iron leaching, was further concentrated by a hydraulic classifier as the upgrading of the rutile sample requires partial removal of impurities and other elements which are detrimental to its end use. The collected impurities and detrimental elements were filtered and dried for analysis by XRF. The XR Fresults are presented in Fig.(10) which it appears that $\mathrm{Fe}(26.31 \%), \mathrm{Si}(37.30 \%), \mathrm{Ca}(9.78 \%), \mathrm{Al}(6.35 \%)$ and $\mathrm{Zn}(5.34 \%)$, being the most detrimental impurities. Also, a smaller amount of $\mathrm{Pb}(2.24 \%)$, $\mathrm{K}(1.32 \%), \quad \mathrm{Mn}(1.84 \%), \mathrm{Zr}(0.33 \%), \quad \mathrm{V}(0.27 \%)$,
$\mathrm{Cr}(0.75 \%)$ and $\mathrm{Sr}(0.23 \%)$ were liberated and removed from the rutile sample using hydraulic classifier.

The rutile sample taken from the hydraulic classifier was then concentrated by means of a shaking table using different inclinations and flow rates. The best results were obtained at a flow rate of $1.3 \mathrm{~L} / \mathrm{min}$ and an inclination of 2.0 degree. As a result of using the shaking table, two grades of rutile were separated grade A and B where they are dried for analysis by XRF. The obtained results in Figs. (11 and 12) indicate that using the shaking table technique improves $\mathrm{Ti}$ content from $62.96 \%$ to $95.81 \%$ for the grade " $\mathrm{A}$ "' and to $80.37 \%$ for grade "B". On the other hand iron content was reduced from $12.32 \%$ to almost zero $\%$, Si from $4.36 \%$ to almost zero $\%, \mathrm{Zr}$ from $10.43 \%$ to $1.83 \%$ for the grade "A". It, also, reduces the iron content from $12.32 \%$ to $8.76 \%$, Si from $4.36 \%$ to $1.63 \%, \mathrm{Zr}$ from $10.43 \%$ to $6.98 \%, \mathrm{~V}$ from $1.06 \%$ to $0.40 \%$ and Cr from $1.69 \%$ to $0.32 \%$.

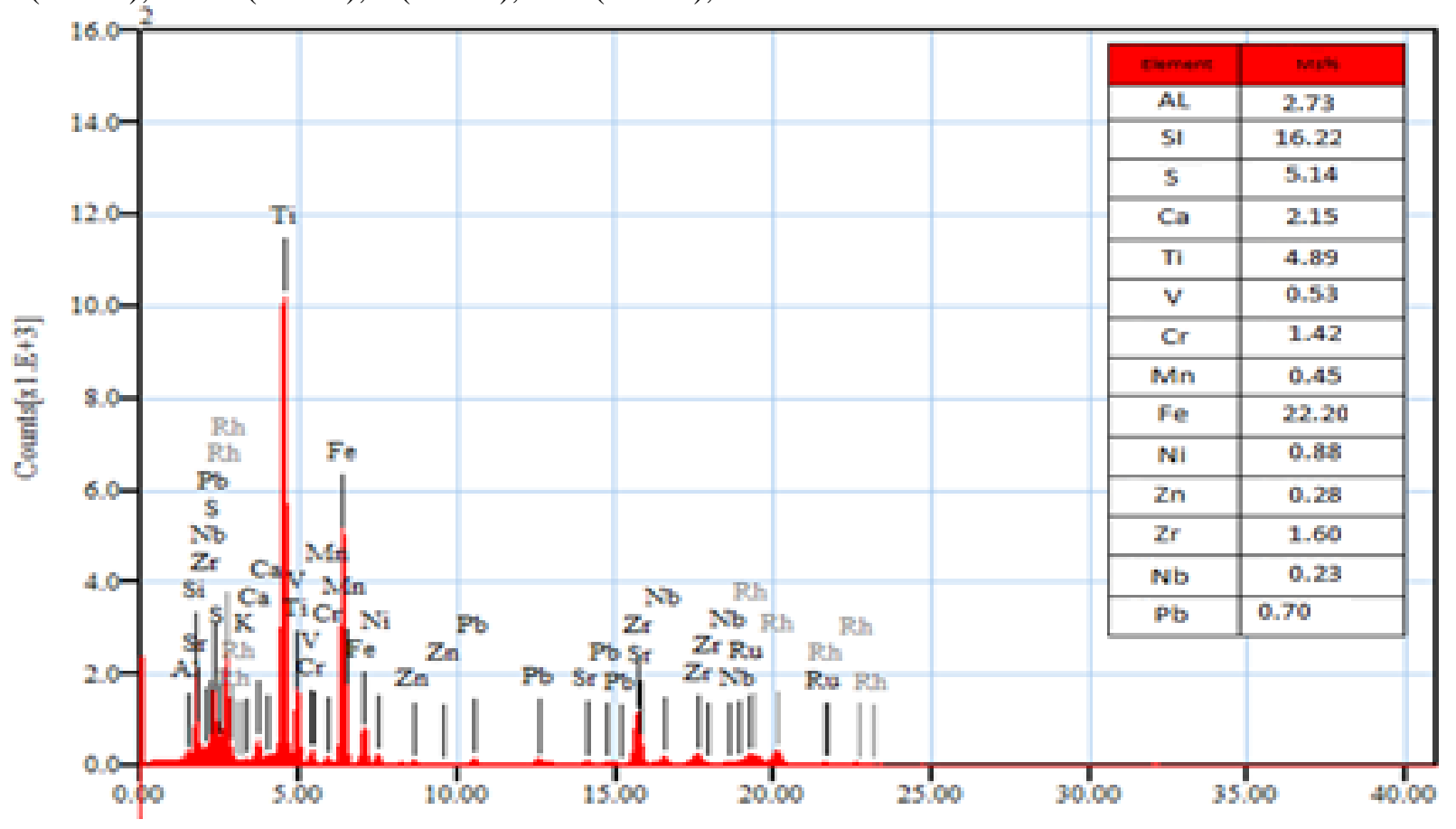

Fig.(9): XRF pattern of the collected impurities from the leaching process 


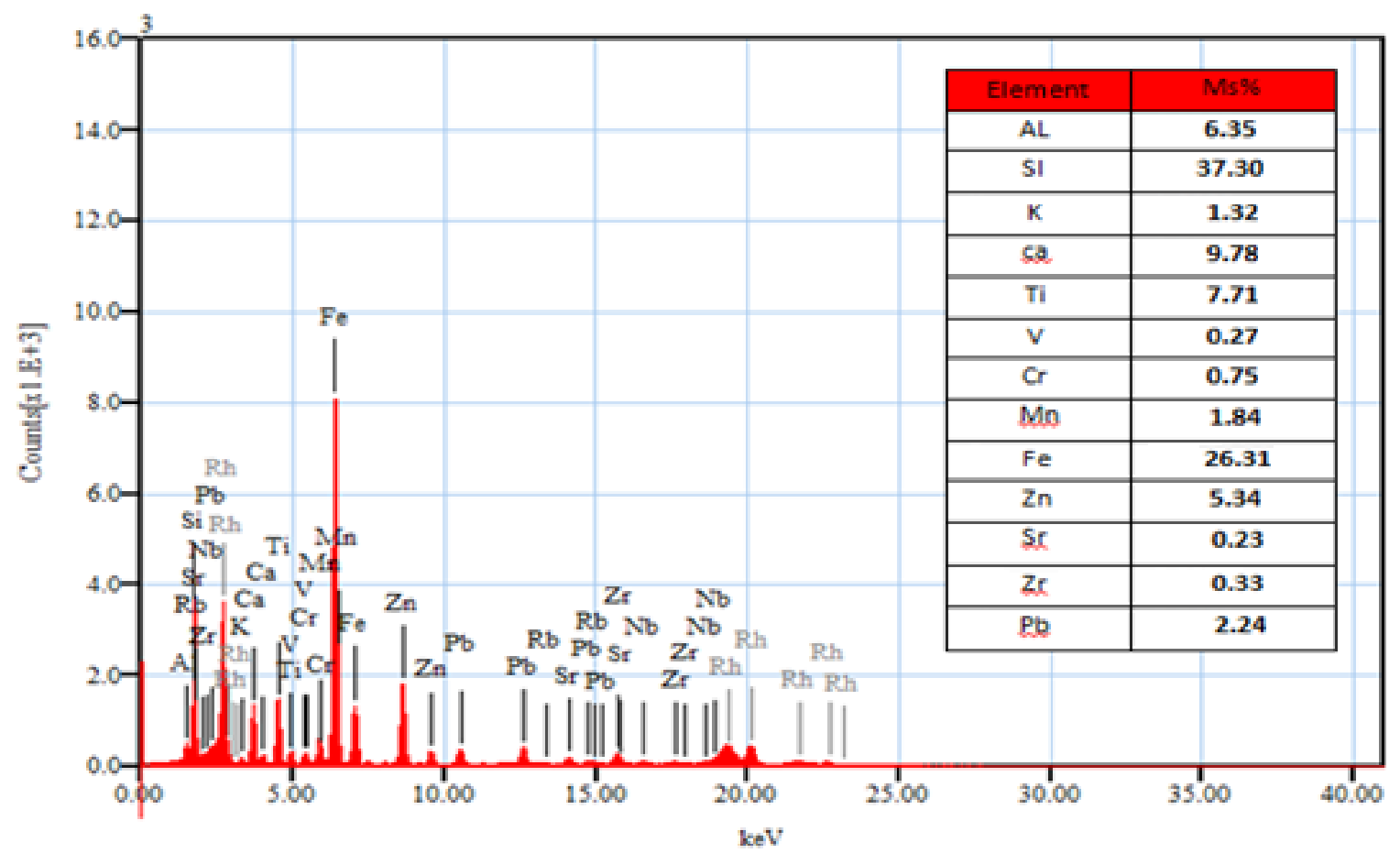

Figure (10): XRF pattern of the collected impurities and detrimental elements from the hydraulic classifier

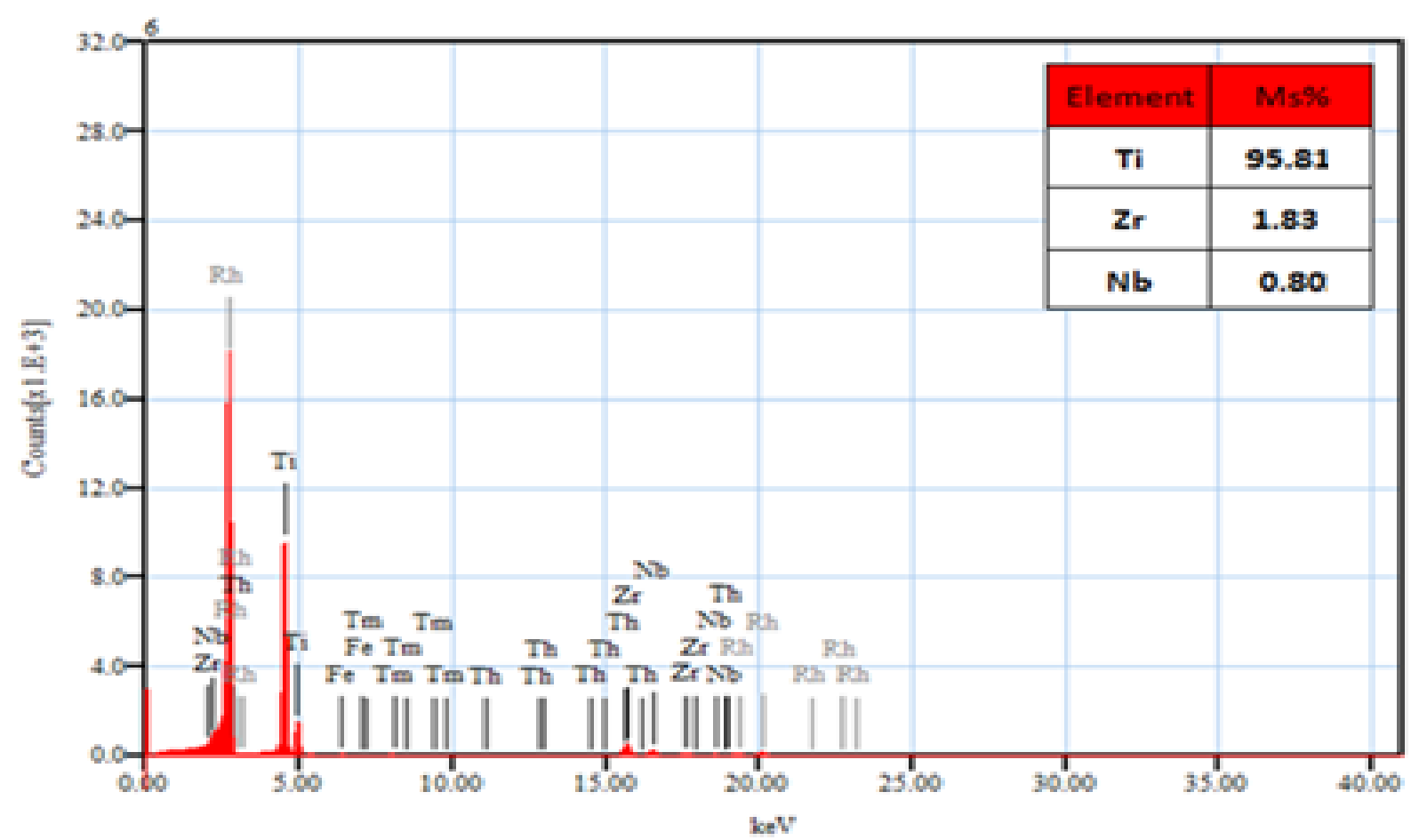

Figure (11): XRF pattern of concentrate (A) from the shaking table 
Grade "B" from shaking table was also subjected to magnetic separation, using an induced roll separator. The results are shown in Figure (13). The comparison between Figs.(12 and 13)indicate that magnetic separation improves Ti content of grade "B" from $80.37 \%$ to $89.58 \%$ and reduces the iron content from $8.76 \%$ to almost zero\%.

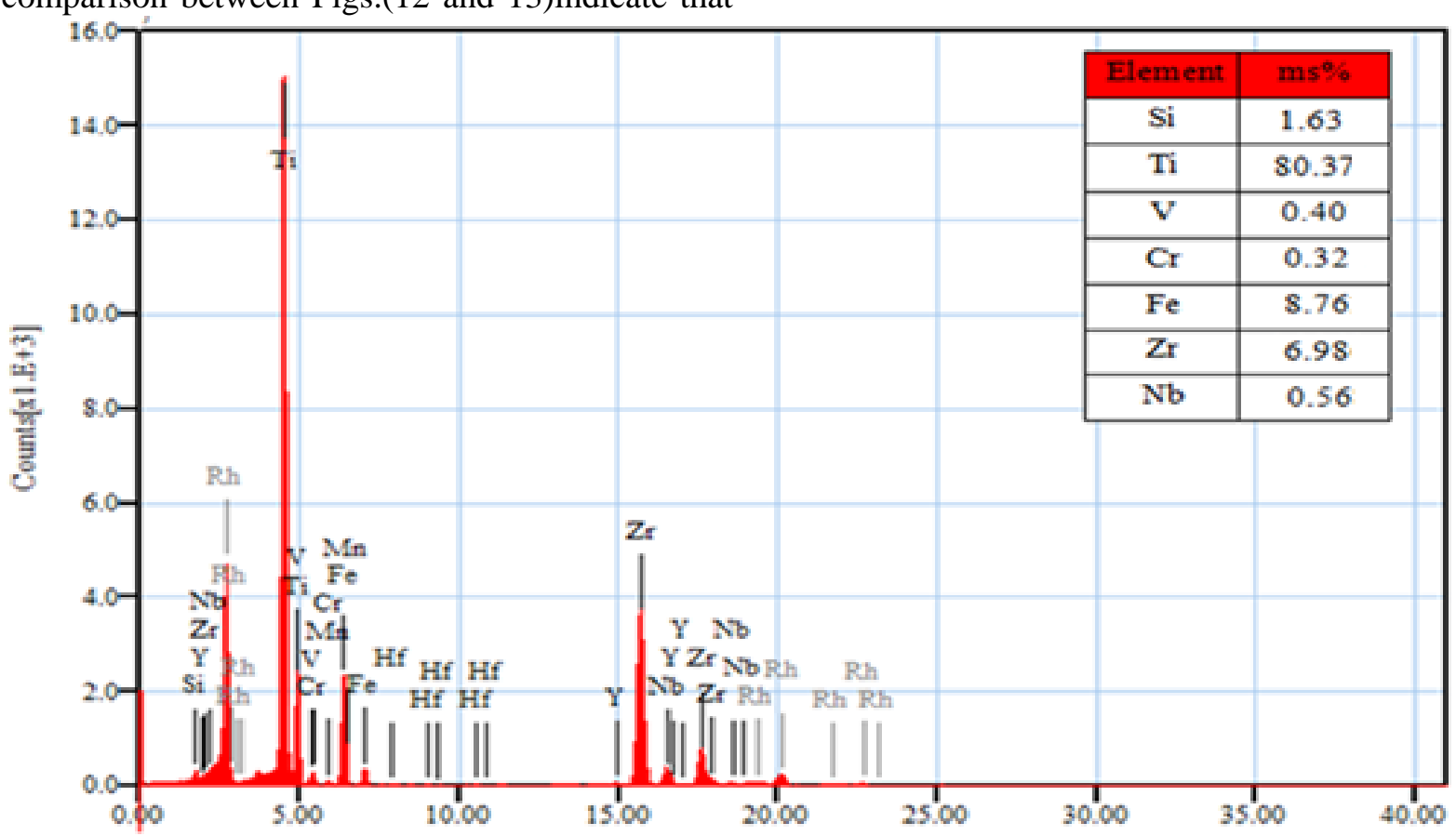

Figure (12): XRF pattern of concentrate (B) from the shaking table

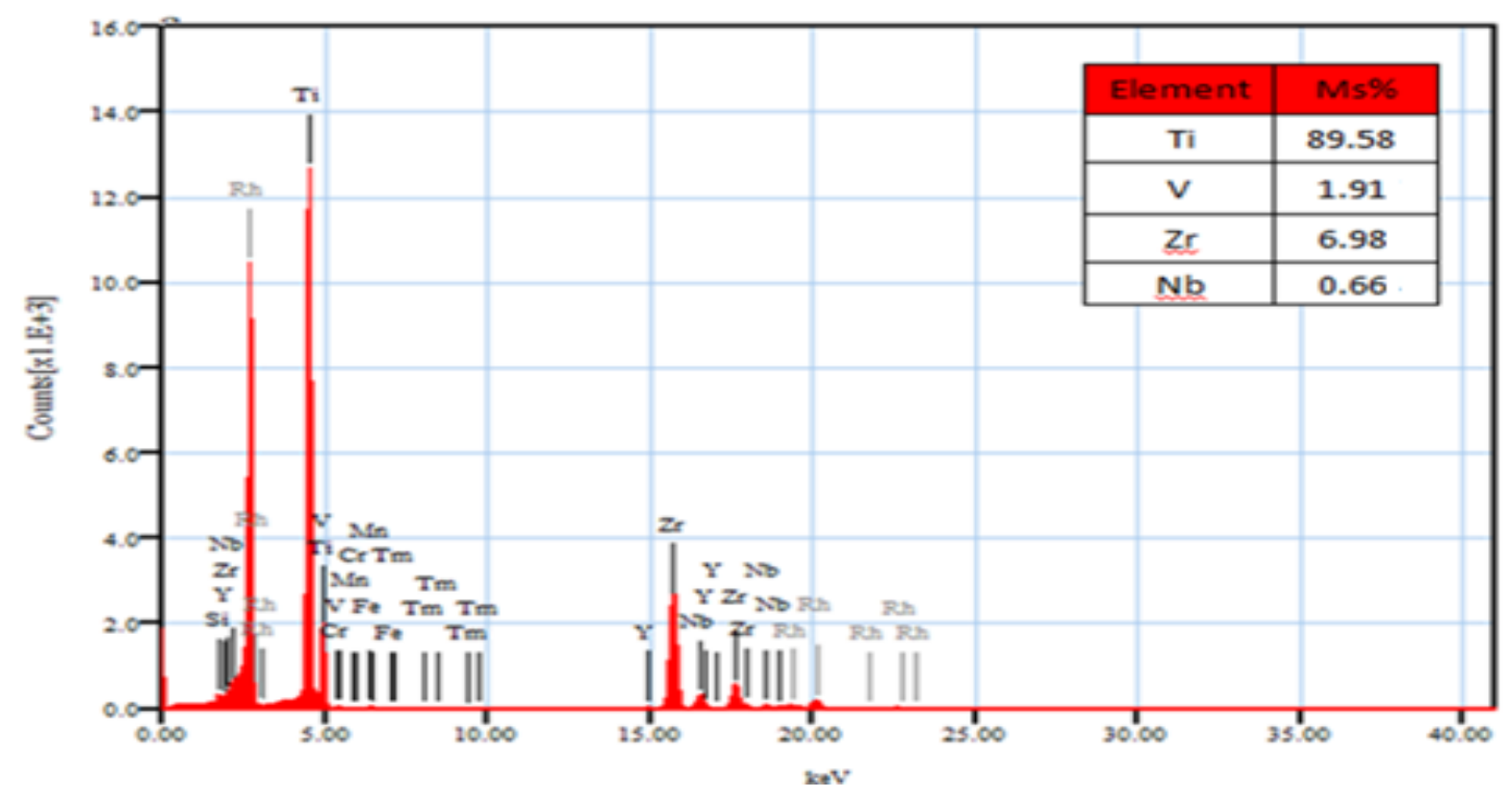

Figure (13): XRF pattern of concentrate (B) after subjected to magnetic separate 
Finally, the original rutile and its upgraded samples were investigated as grains spread on a glass slide (10slides for each sample) using the stereomicroscope for making restriction for number of metal granules existing on each of the slides of these samples. Identification of average purity degree of each of the samples are given in Tables from (1 to 5).

Table (1): Modal analysis of the original rutile sample

\begin{tabular}{|c|c|c|c|c|c|c|c|c|c|}
\hline $\begin{array}{c}\text { sample } \\
\text { No. }\end{array}$ & $\begin{array}{c}\text { Ruti } \\
\text { le }\end{array}$ & Ilmenite & Leucoxene & Sphen & Zircon & $\begin{array}{c}\text { Sec.iron } \\
\text { oxid }\end{array}$ & Epidot & Silica & Hematite \\
\hline 1 & 143 & 73 & 6 & 58 & 29 & 8 & 4 & 11 & 12 \\
\hline 2 & 184 & 90 & 10 & 80 & 40 & 10 & 5 & 15 & 7 \\
\hline 3 & 71 & 28 & 2 & 15 & 12 & 4 & 2 & 3 & 5 \\
\hline 4 & 113 & 64 & 6 & 49 & 25 & 6 & 6 & 13 & 8 \\
\hline 5 & 97 & 49 & 10 & 38 & 24 & 5 & 3 & 6 & 4 \\
\hline 6 & 209 & 103 & 17 & 78 & 42 & 10 & 5 & 10 & 16 \\
\hline 7 & 58 & 27 & 3 & 26 & 14 & 3 & 6 & 3 & 4 \\
\hline 8 & 122 & 51 & 5 & 55 & 28 & 6 & 3 & 13 & 9 \\
\hline 9 & 76 & 38 & 3 & 19 & 15 & 3 & 2 & 2 & 5 \\
\hline 10 & 119 & 66 & 5 & 48 & 26 & 6 & 4 & 3 & 4 \\
\hline Average & 119. & $\mathbf{5 8 . 9}$ & 6.7 & 46.6 & 25.5 & 6.1 & 4 & 7.9 & 7.4 \\
\hline
\end{tabular}

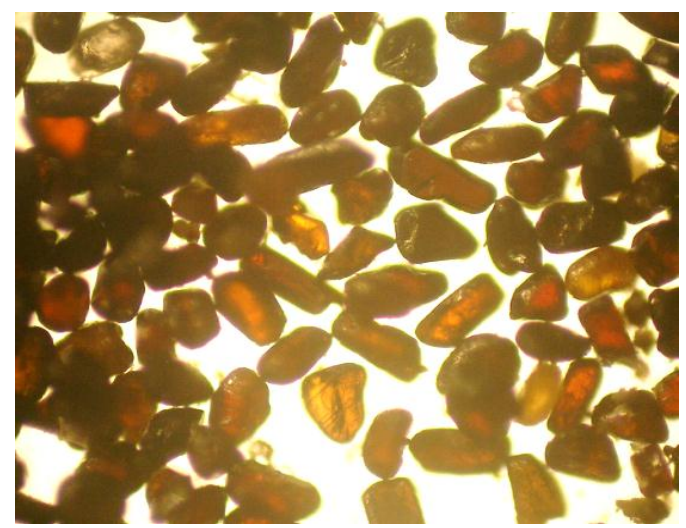

Figure (14): Photomicrograph showing rutile grains of the original rutile sample,(X20)

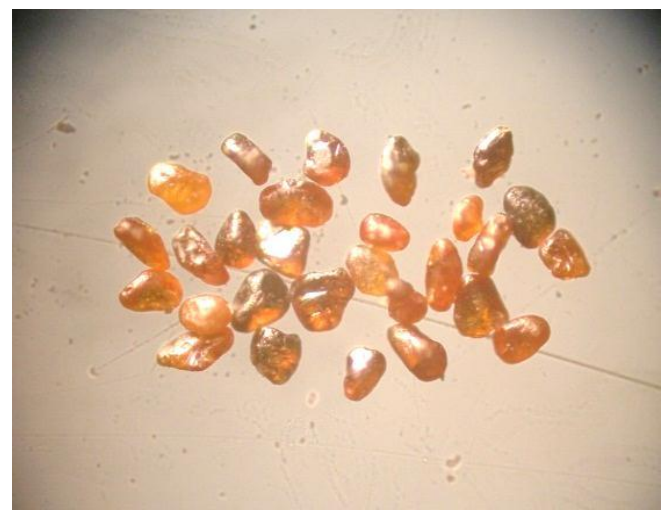

Figure (15): Photomicrograph showing sphen grains of the original rutile sample, $(\mathrm{X20})$ 


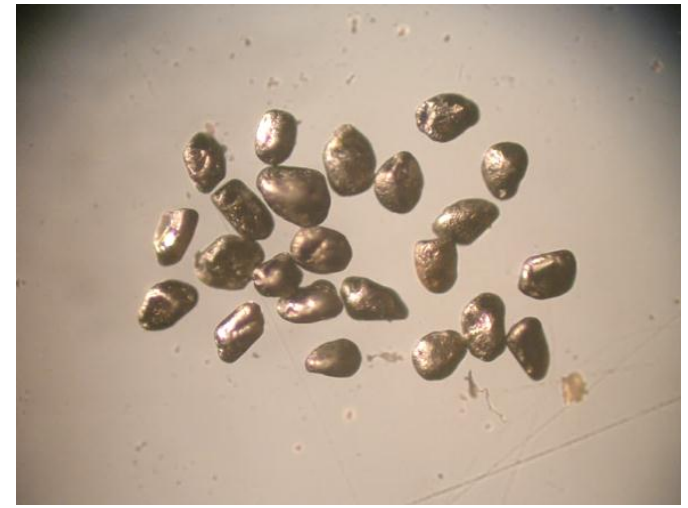

Figure (16): Photomicrograph showingilmenite grains of the original rutile sample, $(\mathrm{X20})$

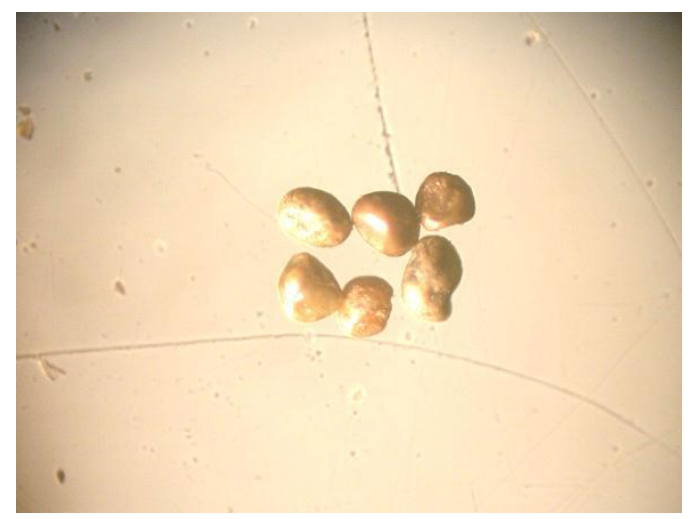

Figure (17): Photomicrograph showing leucoxene grains of the original rutile sample, (X20)

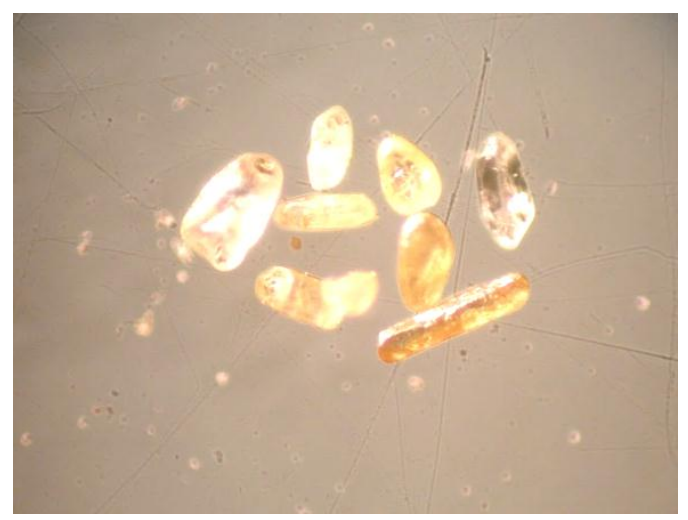

Figure (18): Photomicrograph showing zircon grains of the original rutile sample, $(\mathrm{X20})$

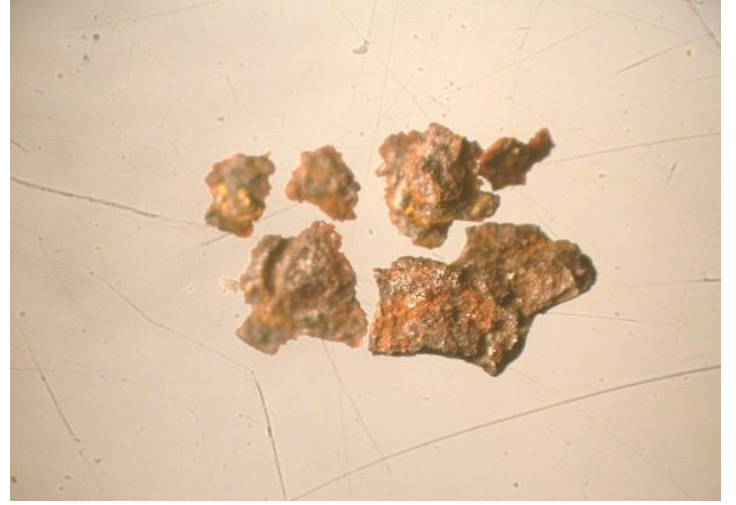

Figure (19): Photomicrograph showing secondary iron oxide grains of the original rutile sample, $(\mathrm{X} 40)$

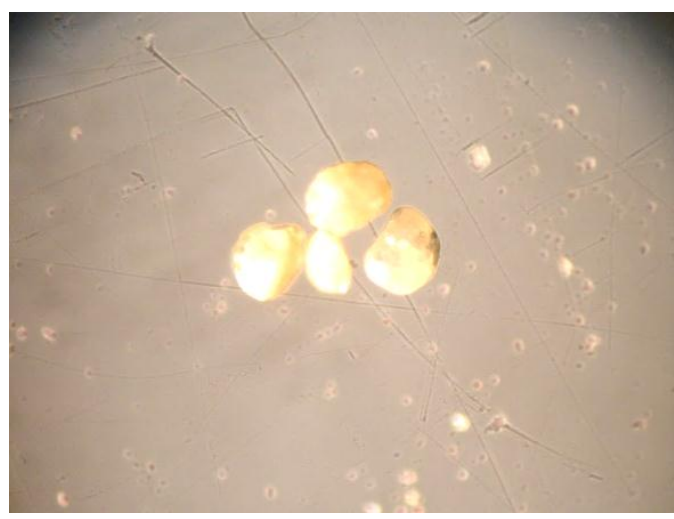

Fig.(20):Photomicrograph showing epidot grains of the original rutile sample, $(\mathbf{X 2 0})$

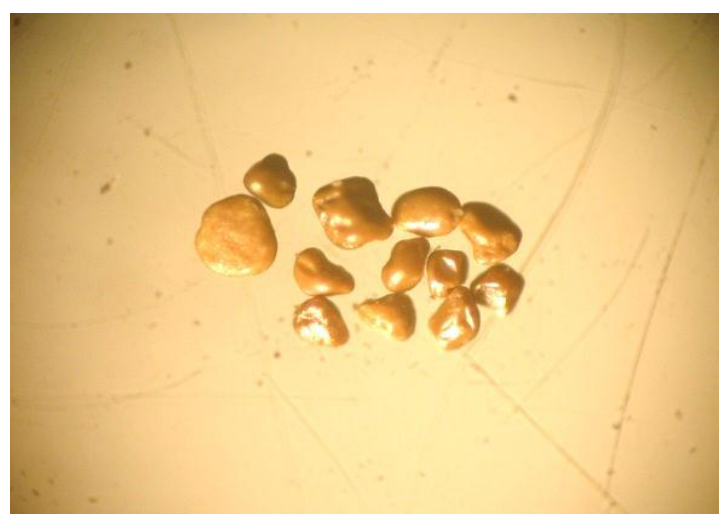

Fig.(21):Photomicrograph showing hematite grains of the original rutile sample, $(\mathrm{X20})$ 


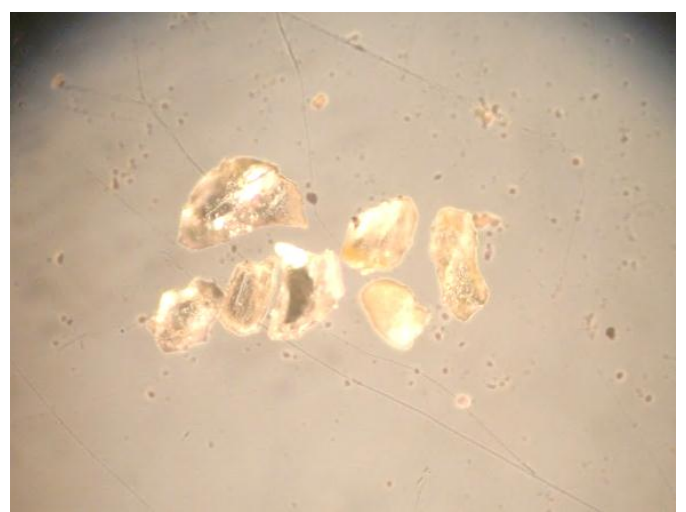

Fig.(22):Photomicrograph showing silica grains of the original rutile sample, (X20)

Table(2): A model analysis of the treatment sample by leaching process

\begin{tabular}{|c|c|c|c|c|c|c|c|}
\hline sample No. & Rutile & Sphen & Leucoxene & Ilmenite & Zircon & Epidot & Silica \\
\hline 1 & 121 & 60 & 14 & 15 & 17 & 4 & 8 \\
\hline 2 & 173 & 78 & 24 & 23 & 24 & 6 & 14 \\
\hline 3 & 141 & 70 & 16 & 17 & 19 & 5 & 10 \\
\hline 4 & 91 & 37 & 14 & 12 & 11 & 3 & 8 \\
\hline 5 & 37 & 18 & 4 & 4 & 3 & 1 & 2 \\
\hline 6 & 67 & 41 & 8 & 9 & 7 & 2 & 6 \\
\hline 7 & 79 & 39 & 8 & 8 & 6 & 2 & 5 \\
\hline 8 & 110 & 70 & 17 & 15 & 10 & 5 & 10 \\
\hline 9 & 121 & 59 & 12 & 12 & 9 & 3 & 7 \\
\hline 10 & 102 & 38 & 21 & 17 & 7 & 3 & 6 \\
\hline Average & 104.2 & 51 & 13.8 & 13.2 & 11.3 & 3.4 & 7.6 \\
\hline
\end{tabular}

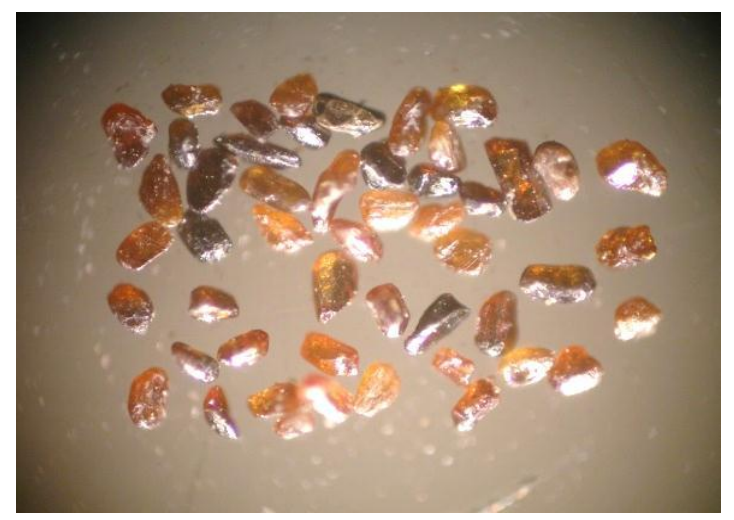

Figure (23): Photomicrograph showing rutile grains of the treatment sample by leaching process, $(\mathrm{X20})$

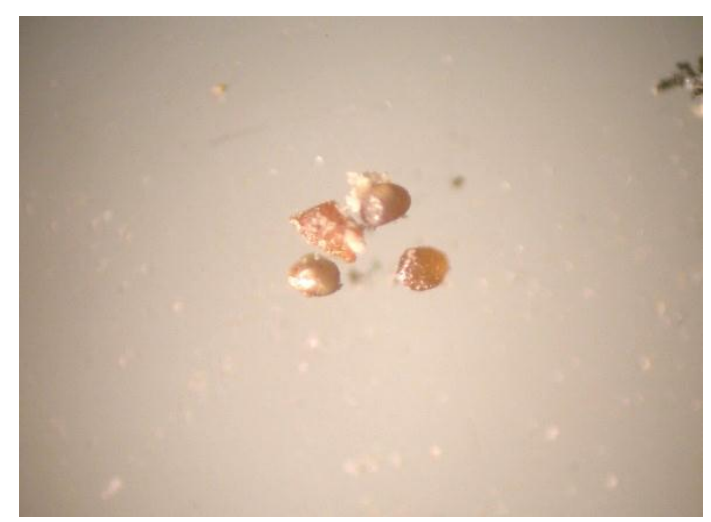

Fig. (24): Photomicrograph showing sphengrains of the treatment sample by leaching process, $(\mathrm{X20})$ 


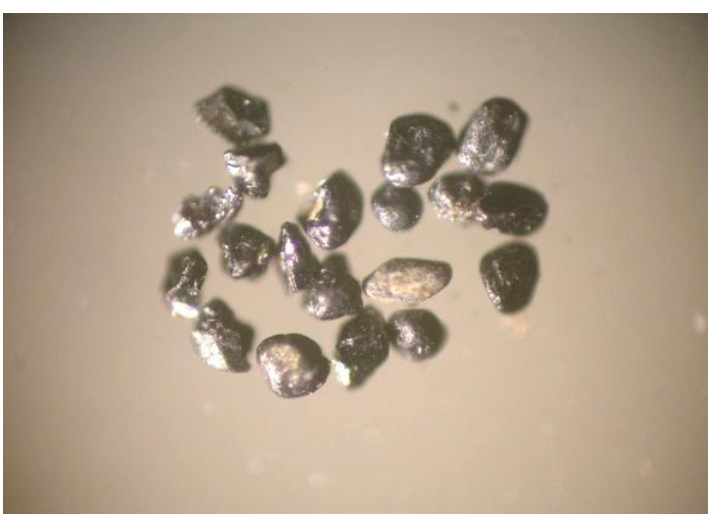

Figure (25): Photomicrograph showing ilmenite grains of the treatment sample by leaching process, (X20)

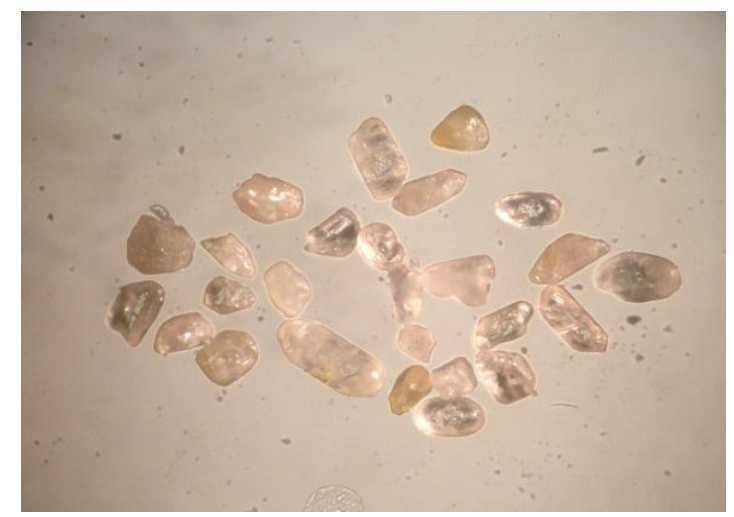

Figure (26): Photomicrograph showing zircon grains of the treatment sample by leaching process, (X20)

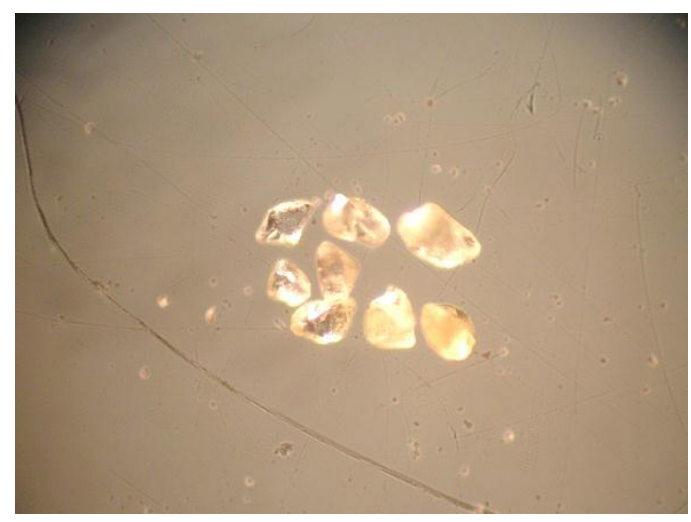

Figure (27): Photomicrograph showing silica grains of the treatment sample by leaching process, (X20)

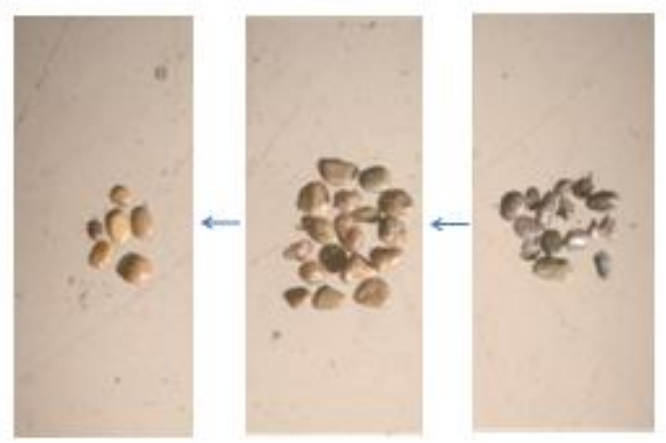

Figure (28): Photomicrograph showing the various stages for transformation of ilmenite to leucoxene due to leaching process, (X20)

Table (3): Modal analysis of the separated sample from the gravimetric separation (grade A)

\begin{tabular}{|c|c|c|c|}
\hline \multirow{2}{*}{ sample No. } & Rutile & Sphen & Zircon \\
\hline 1 & 212 & 106 & 17 \\
\hline 2 & 134 & 60 & 8 \\
\hline 3 & 108 & 54 & 9 \\
\hline 4 & 157 & 72 & 15 \\
\hline 5 & 137 & 69 & 11 \\
\hline 6 & 101 & 47 & 9 \\
\hline 7 & 117 & 59 & 9 \\
\hline 8 & 225 & 106 & 112 \\
\hline 9 & 69 & 35 & 5 \\
\hline 10 & 74 & 37 & 3 \\
\hline Average & 133.4 & 64.5 & 19.8 \\
\hline
\end{tabular}




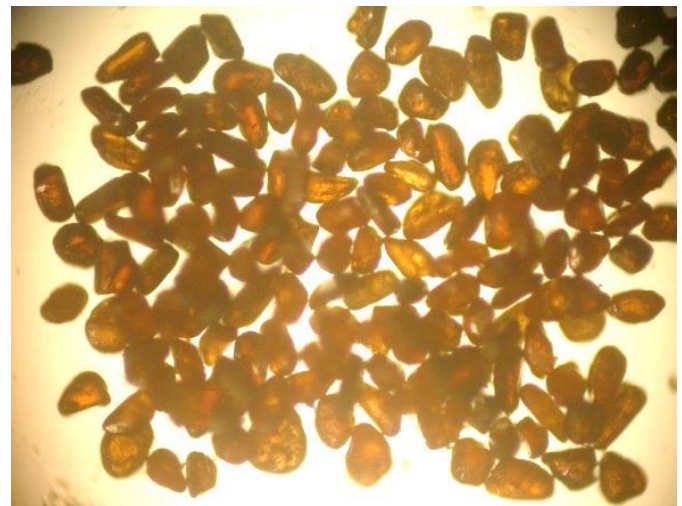

Fig.(29):Photomicrograph showing rutile grains of the separated sample from the gravimetric separation (gradeA),(X20)

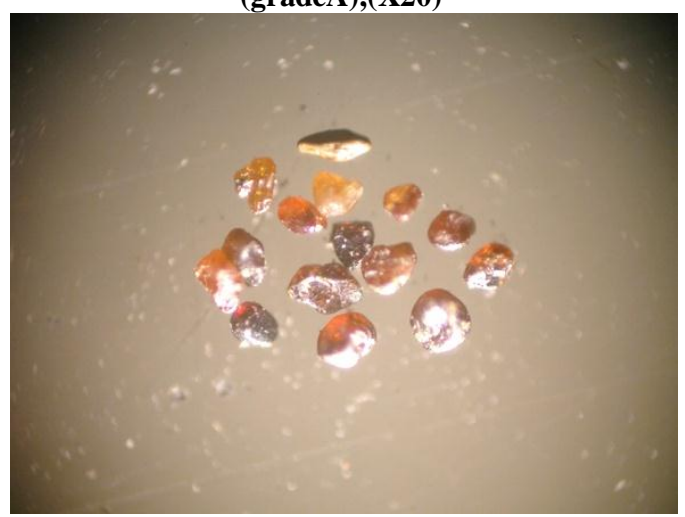

Fig.(30):Photomicrograph showing sphen grains of the separated sample from the gravimetric separation (grade A), (X20)

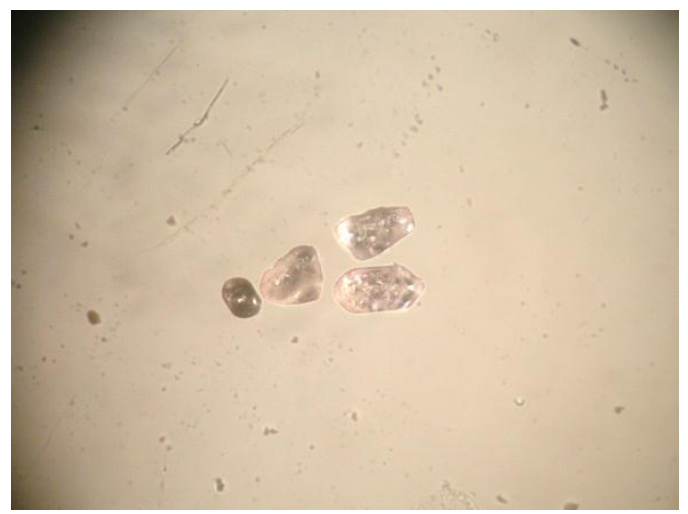

Fig.(31):Photomicrograph showing zircon grains of the separated sample from the gravimetric separation (gradeA),(X20)

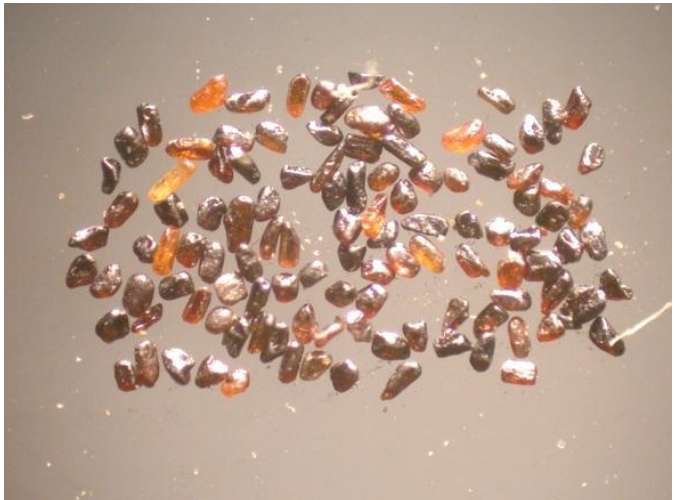

Fig.(32):Photomicrograph showing rutile grains of the separated sample from the gravimetric separation (grade B), (X10)

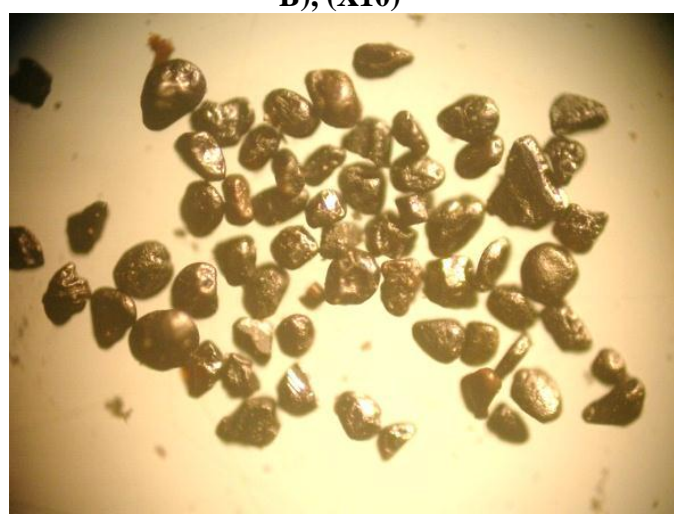

Fig.(33):Photomicrograph showing ilmenite grains of the separated sample from the gravimetric separation (grade B), (X20)

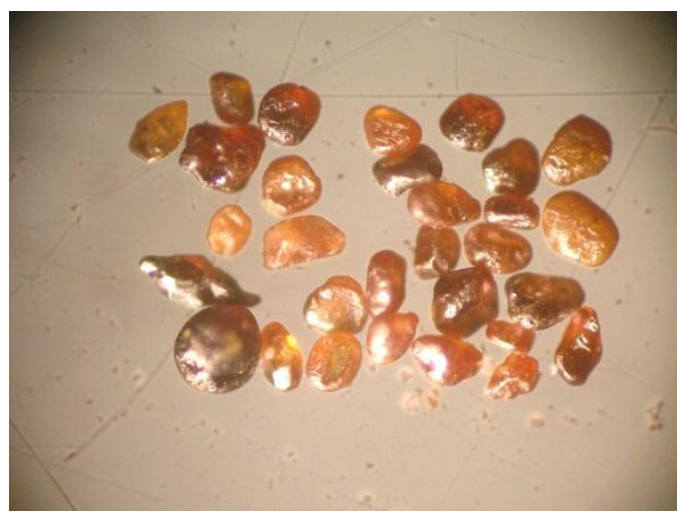

Fig.(34):Photomicrograph showing sphen grains of the separated sample from the gravimetric separation (grade B), (X20) 


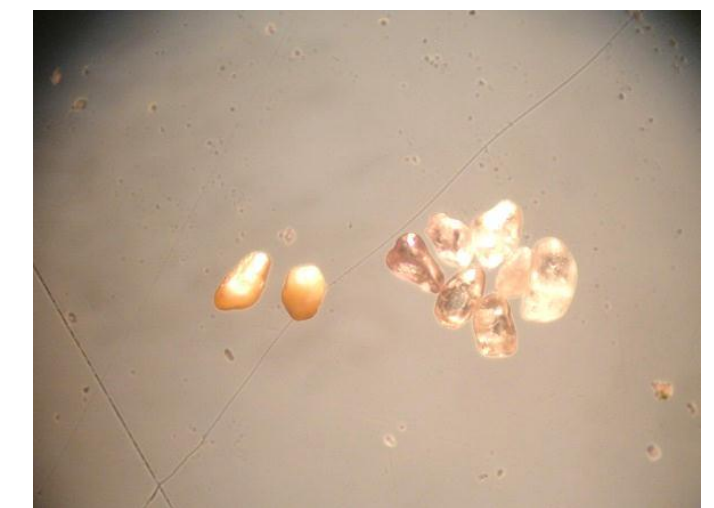

Fig.(35):Photomicrograph showing zircon grains of the separated sample from the gravimetric separation (grade B),(X20)

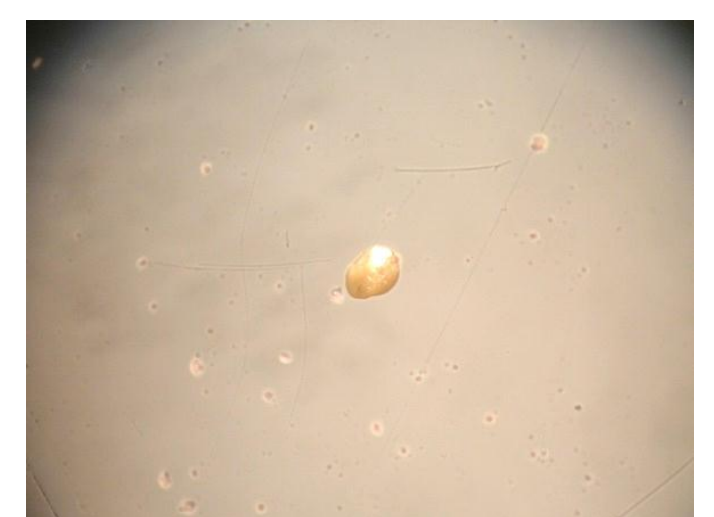

Fig.(36):Photomicrograph showing epidot grains of the separated sample from the gravimetric separation (grade B), $(\mathbf{X 2 0})$

Table (3): Modal analysis of the separated sample from the gravimetric separation (grade A)

\begin{tabular}{|c|c|c|c|}
\hline \multirow{2}{*}{ sample No. } & Rutile & sphen & Zircon \\
\hline 1 & 212 & 106 & 17 \\
\hline 2 & 134 & 60 & 8 \\
\hline 3 & 108 & 54 & 9 \\
\hline 4 & 157 & 72 & 15 \\
\hline 5 & 137 & 69 & 9 \\
\hline 6 & 101 & 47 & 9 \\
\hline 7 & 117 & 59 & 112 \\
\hline 8 & 225 & 106 & 5 \\
\hline 9 & 69 & 35 & 3 \\
\hline 10 & 74 & 64.5 & 19.8 \\
\hline Average & 133.4 & & 97 \\
\hline
\end{tabular}

Table (4): A modal analysis of the separated sample from the gravimetric separation (grade B)

\begin{tabular}{|c|c|c|c|c|c|c|}
\hline sample No. & Rutile & Sphen & Ilmenite & Leucoxene & Zircon & Epidot \\
\hline 1 & 67 & 33 & 11 & 6 & 5 & 3 \\
\hline 2 & 126 & 57 & 25 & 10 & 11 & 5 \\
\hline 3 & 187 & 92 & 31 & 16 & 13 & 8 \\
\hline 4 & 113 & 75 & 21 & 8 & 9 & 4 \\
\hline 5 & 55 & 27 & 9 & 5 & 4 & 2 \\
\hline 6 & 97 & 66 & 14 & 7 & 8 & 3 \\
\hline 7 & 141 & 70 & 23 & 13 & 11 & 6 \\
\hline 8 & 173 & 93 & 31 & 12 & 13 & 5 \\
\hline 9 & 43 & 21 & 7 & 4 & 3 & 2 \\
\hline 10 & 164 & 93 & 25 & 13 & 13 & 7 \\
\hline Average & 116.6 & 62.7 & 19.7 & 9.4 & 9 & 4.5 \\
\hline
\end{tabular}


A.A. El-Shennawy

Table (5): A modal analysis of the separated rutile sample by magnetic separation

\begin{tabular}{|l|l|l|l|l|l|}
\hline $\begin{array}{l}\text { Sample } \\
\text { No. }\end{array}$ & Rutile & Sphen & Zircon & Epidot & Leucoxene \\
\hline 1 & 53 & 28 & 4 & 2 & 5 \\
\hline 2 & 98 & 56 & 7 & 1 & 8 \\
\hline 3 & 116 & 67 & 8 & 3 & 8 \\
\hline 4 & 76 & 36 & 5 & 1 & 9 \\
\hline 5 & 180 & 91 & 12 & 4 & 12 \\
\hline 6 & 161 & 88 & 11 & 3 & 13 \\
\hline 7 & 81 & 43 & 6 & 2 & 7 \\
\hline 8 & 66 & 35 & 5 & 3 & 7 \\
\hline 9 & 131 & 66 & 10 & 4 & 14 \\
\hline 10 & 49 & 26 & 4 & 2 & 5 \\
\hline Average & 101.1 & 5.36 & 7.2 & 2.5 & 8.8 \\
\hline
\end{tabular}

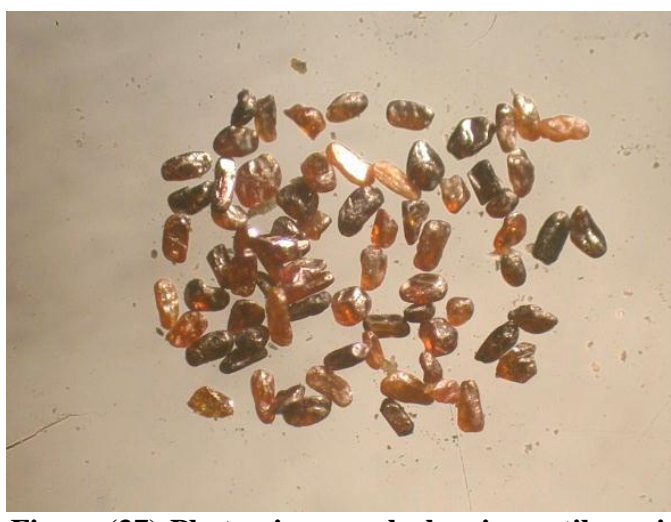

Figure (37):Photomicrograph showing rutile grains of the separated sample by magnetic separation, (X10)

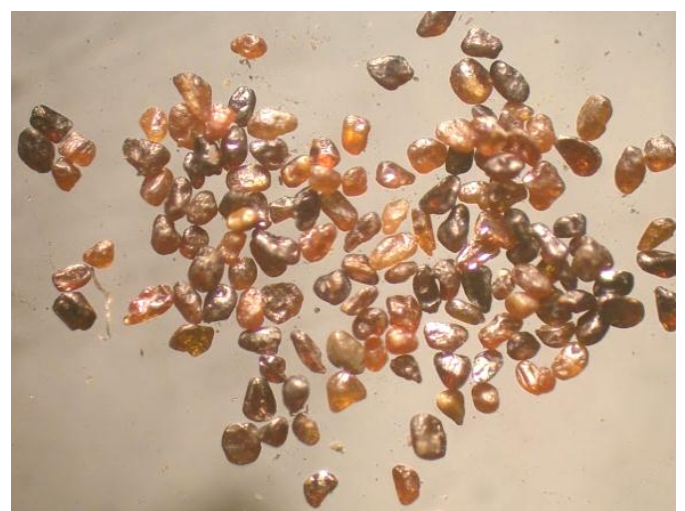

Figure (38):Photomicrograph showing sphen grains of the separated sample by magnetic separation, (X10)

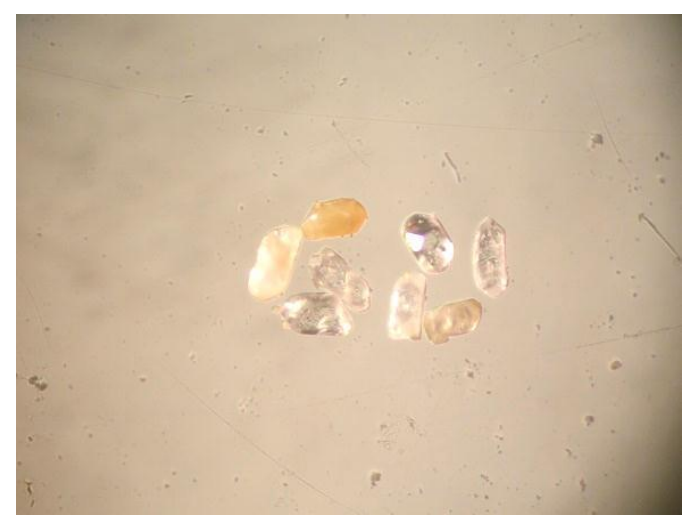

Figure (39): Photomicrograph showing zircon grains of the separated sample by magnetic separation, (X20)

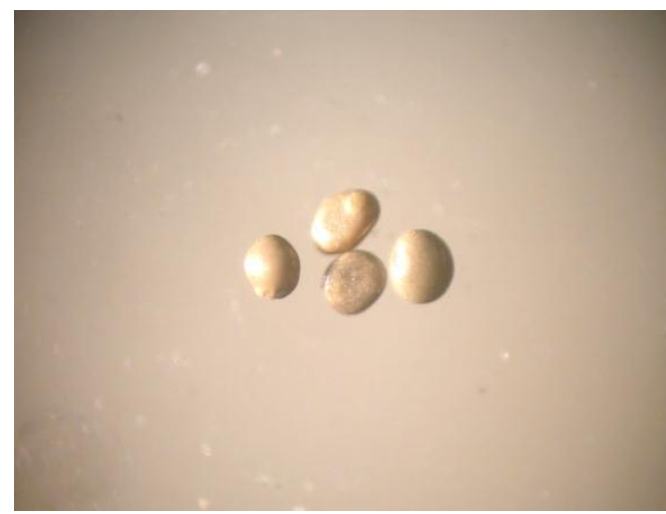

Fig(40):Photomicrograph showing leucoxene grains of the separated sample by magnetic separation, (X20) 
Table (6): The products that have been attained from low grade rutile sample

\begin{tabular}{|c||c|c|c|c||}
\hline \multirow{2}{*}{$\begin{array}{c}\text { Low-grade rutile } \\
\text { sample (62.96\%) }\end{array}$} & \multicolumn{3}{c|}{ Products } \\
\cline { 2 - 5 } & $\begin{array}{c}\text { Rutile with purity } \\
\text { grade (95.81\%) }\end{array}$ & $\begin{array}{c}\text { Rutile with purity } \\
\text { grade (89.58\%) }\end{array}$ & Tails & Loss \\
\hline \hline \multirow{2}{*}{$10 \mathrm{Kg}$} & $4.906 \mathrm{Kg}$ & $2.454 \mathrm{Kg}$ & $1.843 \mathrm{Kg}$ & $0.797 \mathrm{Kg}$ \\
\hline
\end{tabular}

\section{Conclusions}

The following conclusions may be drawn from beneficiation of low-grade rutile sample:

1- Initial characterization showed that the main impurities in the sample are $\mathrm{Fe}(12.32 \%)$ $\mathrm{Zr}(10.43 \%)$ and $\mathrm{Si}(4.36 \%)$.Also, smaller amount of $\mathrm{Zn}(2.16 \%), \mathrm{Ca}(1.69 \%), \mathrm{Cr}(1.69 \%), \mathrm{V}$ $(1.06 \%), \quad \mathrm{Pb} \quad(1.56 \%), \mathrm{Mn}(0 . \quad 98 \%)$ and $\mathrm{Nb}(0.60 \%)$.

2- The results of beneficiation studies reveal that while up-current classifiers, leaching process and hydraulic separation removes majority of these contaminating minerals to give an intermediate product rutile, gravimetric separation and magnetic separation are required to upgrade the rutile.

3- Based on the laboratory study, beneficiation flow sheets have been suggested for the rutile.

\section{References}

1-Anon. (1984) .Classifiers part2: Some of the major manufacturers of classification equipment used in mineral processing, Mining Mag., (July) 40.

2-G.ADabbour. (1980) Geological and mineralogical studies on rutile in the black sand deposits from the Egyptian Med.coast.Ph. D. Thesis, Cairo University, Giza.

3-G.A.Dabbour. (1995). Estimation of the economic minerals reserves in Rosetta beach sands, Egyptian minerals, Vol. 7,PP.1-6.

4-Gambogi J. (2005). US geological survey mineral commodity summaries-titanium and titanium dioxide.

US. Government printing office Reston, Reston,178-179.

5-Linak E, Inoguchi Y. (2005). Chemical economics handbooks: Titanium dioxide, Menlo Park,CA,CRI consulting.

6-Ledgerwood J, Westhuyzen P. (2011).The use of sulphuric acid in the mineral sands industry as a chemical mechanism for iron removal.
7-Manser,R.J.,et al .1991 ) .The shaking table concentrator the influence of operating condition and table parameters on mineral separation-the development of a mathematical model fornormal operating conditions. Minerals Engineering 4 (3/4)369

8-Prinsloo,A. (2006). The formation of chemical precipitates in the HAL process and its

impact on electrostatic separation of zircon and rutile minerals. Stellenbosch: University of

dStellenbosch .

9-Sivamohan, R.,and Forssberg, E . (1985 ).Principle of tabling, Int.J. Min.Proc.15, (NOV.)281

10-Svoboda, J., (1987 ). Magnetic methods for the treatment of minerals, Elsevier,Amsterdam

11-Stoffels, J., (2005 ). Hal reactor optimization. Namakwa sand.

12-Terry, R.L., (1974 ) .Minerals concentration by wet tabling, minerals processing 15 , (July /Aug. ) 14 .

13-Visser, J.D., (2006 ). Hal temperature and acid dosage optimization. Namakwa sands.

14-Wills, B.A., (1981).Laboratory simulation of shaking table performance, Min .Mag. (June)489 .

15-Wills, B.A. (1988). Mineral processing technology, $4^{\text {th }}$ ed, Pergamon press.

16-Wills, (1992). Mineral processing technology, $5^{\text {th }}$ ed., Pergamon, Oxford. 